Supporting Information for:

\title{
Growth of Extra-Large Chromophore Supramolecular Polymers for Enhanced Hydrogen Production
}

Adam J. Dannenhoffer ${ }^{1 *}$, Hiroaki Sai ${ }^{1}{ }^{2}$, Boris Harutyunyan ${ }^{3}$, Ashwin Narayanan $^{1}$, Natalia E. Powers-Riggs ${ }^{4,5}$, Alexandra N. Edelbrock ${ }^{6}$, James V. Passarelli ${ }^{4}$, Steven J. Weigand ${ }^{7}$, Michael R. Wasielewski ${ }^{4,5}$, Michael J. Bedzyk ${ }^{1,3}$, Liam C. Palmer ${ }^{2,4,9}$, Samuel I. Stupp $p^{1,2,4,6,8,9 \S}$

1'Department of Materials Science and Engineering, Northwestern University, 2220 Campus Drive, Evanston, IL 60208, USA.

${ }^{2}$ Center for Bio-Inspired Energy Science, Northwestern University, 2145 Sheridan Road, Evanston, IL 60208, USA

3Department of Physics and Astronomy, Northwestern University, 2145 Sheridan Road, Evanston, IL 60208, USA.

${ }^{4}$ Department of Chemistry, Northwestern University, 2145 Sheridan Road, Evanston, IL 60208, USA.

IInstitute for Sustainability and Energy at Northwestern, Northwestern University, 2145 Sheridan Road, Evanston, IL 60208, USA

${ }^{6}$ Department of Biomedical Engineering, Northwestern University, 2145 Sheridan Road, Evanston, IL 60208, USA.

${ }^{7}$ Dow-Northwestern-DuPont Collaborative Access Team Synchrotron Research Center, Northwestern University, 9700 South Cass Avenue, Argonne, IL 60439 USA ${ }^{8}$ Department of Medicine, Northwestern University, 676 N St. Clair, Chicago, IL 60611, USA.

${ }^{9}$ Simpson Querrey Institute, Northwestern University, 303 E. Superior Street, Chicago, IL 60611, USA.

\footnotetext{
*These authors contributed equally.

§To whom correspondence should be addressed.

E-mail: s-stupp@northwestern.edu
} 


\section{Table of Contents}

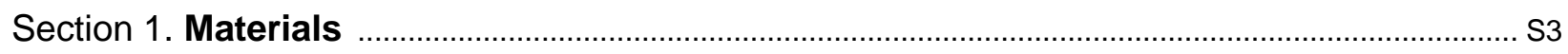

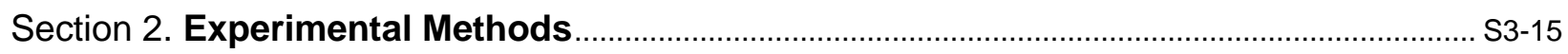

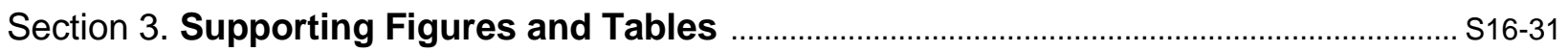

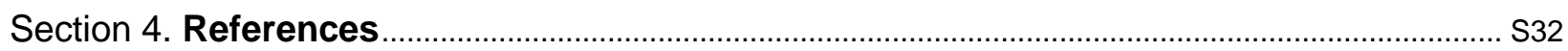




\section{Materials}

Water used for assembly experiments was produced using a Barnstead Nanopure deionization / UV-irradiation unit to achieve 18.2 M 2 -cm resistivity before use. All other chemicals were purchased from Sigma-Aldrich and used without further purification unless otherwise noted. $\mathrm{N}, \mathrm{N}$-dimethylformamide (DMF) and $\mathrm{N}, \mathrm{N}$-diisopropylethylamine (DIPEA) were dried on a solvent purification system. ${ }^{1} \mathrm{H}$ NMR spectra were acquired using an Agilent DD MR$400(400 \mathrm{MHz})$ and ${ }^{13} \mathrm{C}$ NMR spectra using a Bruker AVANCE III (500 MHz, direct cryoprobe). High-resolution mass spectrometry was acquired using an Agilent 6210 LC-TOF (ESI, APCI, APPI) instrument.

\section{Experimental Methods}

Synthesis of PMI-L5 (1)
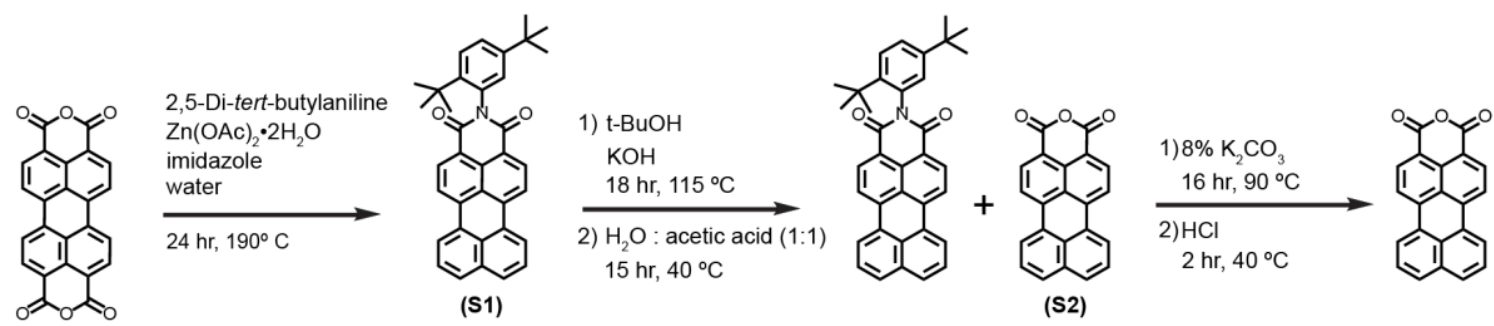

(S2)

Scheme 1: Synthesis of PMA.

\section{Synthesis of N-(2,5-di-tert-butylphenyl) perylene-3,4-dicarboximide (S1, PMI-DTBA) ${ }^{1}$}

The synthetic procedure was adapted from Refs. 1 and 2. Perylene-3,4,9,10tetracarboxylic dianhydride (PDA) (38.4 g, $97.8 \mathrm{mmol}), 2,5$-di-tert-butyl aniline (9.98 g, $48.6 \mathrm{mmol})$, zinc acetate dihydrate $(13.9 \mathrm{~g}, 63.3 \mathrm{mmol})$, and imidazole $(189 \mathrm{~g})$ were mixed thoroughly in a beaker. The mixture was transferred to a $600 \mathrm{~mL}$ glass liner (Parr Instrument Co., Part number $762 \mathrm{HC} 3)$, and water $(80 \mathrm{~mL})$ was added in two portions while mixing with a spatula to ensure the components are evenly dispersed. The liner was placed within a pressure vessel (Parr Instrument Co. Series 4625 High Pressure Vessel), then the vessel was sealed and connected to a heating mantle with a temperature controller. The vessel was placed behind a blast shield and heated to $190{ }^{\circ} \mathrm{C}$ for 24 hours. The reaction mixture was allowed to cool to room temperature. The residue was removed from the glass liner using chloroform $(1.5 \mathrm{~L})$ and the organics washed with $400 \mathrm{~mL}$ of $0.5 \mathrm{M} \mathrm{HCl}_{\text {aq }}$ three times to remove imidazole and zinc acetate. Note that at this step the organic and aqueous layers both appear very dark and can be difficult to separate. The organic layer was collected and the solvent was removed using a 
rotary evaporator to obtain a red solid. Flash chromatography $\left(\mathrm{SiO}_{2}\right.$, using chloroform as the eluent) gave $1(\sim 15 \mathrm{~g})$ as a red solid.

${ }^{1} \mathrm{H}$ NMR (499 MHz, $\left.\mathrm{CDCl}_{3}, 25^{\circ} \mathrm{C}\right): \delta=8.64(\mathrm{~d}, 2 \mathrm{H}), 8.45(\mathrm{~m}, 4 \mathrm{H}), 7.91(\mathrm{~d}, J=8.1 \mathrm{~Hz}, 2 \mathrm{H}), 7.64$ (t, $J=7.8$ $\mathrm{Hz}, 2 \mathrm{H}), 7.59$ (d, J = 8.7 Hz, 1H), 7.45 (dd, $J=8.6,2.2 \mathrm{~Hz}, 1 \mathrm{H}), 7.03(\mathrm{~d}, J=2.2 \mathrm{~Hz}, 1 \mathrm{H}), 1.34(\mathrm{~s}, 9 \mathrm{H})$, $1.30 \mathrm{ppm}(\mathrm{s}, 9 \mathrm{H})$.

${ }^{13} \mathrm{C}$ NMR $\left(126 \mathrm{MHz}, \mathrm{CDCl}_{3}\right) \delta=164.97,149.98,143.79,137.51,134.33,133.07,131.93,130.96,130.35$, 129.26, 128.70, 128.01, 127.82, 127.08, 126.13, 123.82, 121.34, 120.24, 35.53, 34.25, 31.74, 31.26 ppm. HRMS (ESI-TOF-MS): Expected $\mathrm{m} / z$ : (509.2355), Observed $\mathrm{m} / z$ : $510.2427\left(M+\mathrm{H}^{+}\right)$.

\section{Perylene-3,4-dicarboxylic anhydride (S2, PMA) ${ }^{1}$}

The synthetic procedure was adapted from Refs. 1 and 2. To a $500 \mathrm{~mL}$ round bottom flask equipped with stir bar were added PMI-DTBA (2.5 g, $4.9 \mathrm{mmol}), \mathrm{KOH}$ (10 g, $178.2 \mathrm{~mol}$ ), and tert-butanol $(200 \mathrm{~mL})$. The flask was fitted with a water condenser and placed in an oil bath to reflux overnight. The reaction mixture was cooled and poured into $\mathrm{AcOH} / \mathrm{H}_{2} \mathrm{O} 1: 1$ solution $(\mathrm{v} / \mathrm{v}, 650 \mathrm{~mL})$. The mixture was stirred at $40^{\circ} \mathrm{C}$ for $18 \mathrm{~h}$ to allow precipitation, filtered and washed with water $(500 \mathrm{~mL})$. The filtrate showed a faint orange color. The solid was suspended in $8 \%$ aqueous potassium carbonate solution $(1.2 \mathrm{~L})$, heated and stirred at $90^{\circ} \mathrm{C}$ for 6 hours. This step allows dissolution of all the PMA as water-soluble perylene-3,4-dicarboxylate dipotassium salt, while leaving the PMI undissolved. The solution was yellow and fluoresced in blue color when irradiated with a $365 \mathrm{~nm}$ UV lamp, with red solids dispersed. The suspension was filtered hot and washed with $500 \mathrm{~mL}$ of water $\left(90^{\circ} \mathrm{C}\right)$ to yield a yellow florescent filtrate. The red solid on the filter paper is the remaining PMI-DTBA starting material and can be reused for subsequent reactions without further purification. The filtrate was allowed to cool to $40^{\circ} \mathrm{C}$, during which crystals of the perylene dicarboxylate dipotassium salt form. The $\mathrm{pH}$ was adjusted via slow addition of concentrated $\mathrm{HCl}_{\mathrm{aq}}(37 \%)$ with stirring at $40^{\circ} \mathrm{C}$. During this step, the solution lost its yellow color and florescence, a brown solid formed, and the solution evolved carbon dioxide most vigorously before the $\mathrm{pH}$ drops below 5 . Addition of a minimal amount of $\mathrm{MeOH}$ from a squirt bottle was used to break the bubbles formed and minimize any overflow. Once the $\mathrm{pH}$ dropped below 3, the mixture was left to stir for $1 \mathrm{~h}$ and was filtered to give $\mathbf{S 2}(\sim 1 \mathrm{~g})$ as a brown solid. 


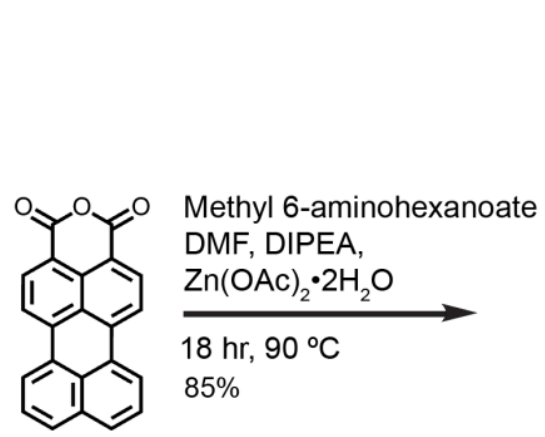

(S2)

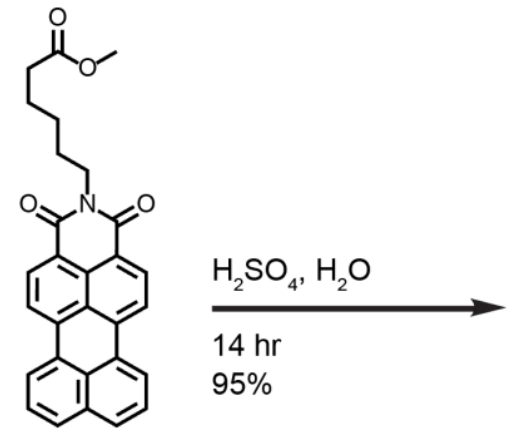

(S3)

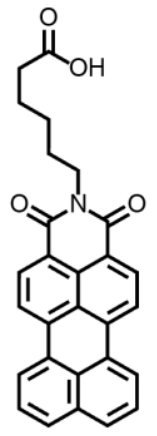

(1)

Scheme 2: Synthesis of $\mathrm{N}$-(O-methyl-6-carboxyhexyl) perylene-3,4dicarboximide.

\section{Synthesis of N-(O-methyl-5-carboxypentyl) perylene-3,4-dicarboximide (S3) ${ }^{1}$ :}

A round bottom flask $(250 \mathrm{~mL})$ was filled with $\mathbf{S 2}(500 \mathrm{mg}, 1.55 \mathrm{mmol})$, zinc acetate dihydrate $(10 \mathrm{mg})$, DMF (100 mL), DIPEA ( $870 \mu \mathrm{L}, 5 \mathrm{mmol})$, and methyl 6-aminohexanoate (665 mg, $4.65 \mathrm{mmol})$. The solution was stirred and heated at $85^{\circ} \mathrm{C}$ for 18 hours at which point the solution is a deep brownish red color. We note that PMA is not fully soluble at room temperature. Once the solution had cooled to room temperature it was poured into $300 \mathrm{~mL}$ of $0.5 \mathrm{M} \mathrm{HCl}_{\text {aq. }}$. The resulting red solid was filtered using a Büchner funnel and washed with $500 \mathrm{~mL}$ of water. Once dry, the solid was dissolved in DCM and placed on a silica column with DCM as the mobile phase. DCM was passed through the column to remove any perylene or other lower polarity compounds, after which the mobile phase was switched to $1 \%$ methanol in $\operatorname{DCM}(\mathrm{v} / \mathrm{v})$, at which point a dark red band moves through column. The product was collected to obtain $620 \mathrm{mg}$ of $\mathrm{N}$-(O-methyl-5-carboxypentyl) perylene-3,4-dicarboximide. The compound was further purified by recycling gel permeation chromatography (JAI LC-9110 NEXT) before deprotection. Yield: $85 \%$.

${ }^{1} \mathrm{H}$ NMR (499 MHz, $\left.\mathrm{CDCl}_{3}\right) \delta 7.91(\mathrm{~d}, J=7.8 \mathrm{~Hz}, 2 \mathrm{H}), 7.73(\mathrm{~d}, J=7.5 \mathrm{~Hz}, 2 \mathrm{H}), 7.57(\mathrm{~m}, J=7.8 \mathrm{~Hz}, 4 \mathrm{H})$, 7.26 (t, $J=7.7 \mathrm{~Hz}, 2 \mathrm{H}), 4.04(\mathrm{t}, J=7.8 \mathrm{~Hz}, 2 \mathrm{H}), 3.70(\mathrm{~s}, 3 \mathrm{H}), 2.39(\mathrm{t}, J=7.5 \mathrm{~Hz}, 2 \mathrm{H}), 1.76(\mathrm{~m}, J=7.8 \mathrm{~Hz}$, $4 \mathrm{H}), 1.50$ (p, $J=7.9 \mathrm{~Hz}, 2 \mathrm{H}) .{ }^{13} \mathrm{C}$ NMR $\left(126 \mathrm{MHz}, \mathrm{CDCl}_{3}\right) \delta 174.09,163.31,136.00,133.68,130.46$, $130.41,128.72,128.30,126.92,126.47,125.59,122.92,120.06,119.35,51.52,40.03,34.04,27.72$, 26.76, 24.72.

HRMS (ESI-TOF-MS): Expected m/z: (449.1632), Observed m/z: $\left(450.1705, \mathrm{M}^{+} \mathrm{H}^{+}\right)$

Note: the temperature needed for the condensation reaction depends on the amine used. For simple primary amines lower temperatures can work. For bulky amines higher temperatures are 
required. In the most hindered cases, DMF must be replaced with imidazole and the reaction run at $140{ }^{\circ} \mathrm{C}$.

\section{Synthesis of $\mathrm{N}$-(5-carboxypentyl) perylene-3,4-dicarboximide (1) ${ }^{1}$ :}

S3 (30 mg) in a scintillation vial was dissolved in $8 \mathrm{~mL}$ of $\mathrm{H}_{2} \mathrm{SO}_{4}$, and $2 \mathrm{~mL}$ of water was added dropwise, swirling the solution every 5-10 drops. The reaction proceeded for 5 hours at room temperature, then quenched by the addition of $100 \mathrm{~mL}$ of water leading to the formation of a brown/red precipitate. Subsequently the solid was filtered using a Büchner funnel and washed with $500 \mathrm{~mL}$ of water. The final compound was collected from the filter paper by dissolving in $3: 1$ $\mathrm{DCM} / \mathrm{MeOH}(\mathrm{v} / \mathrm{v})$ with sonication, followed by rotary evaporation and drying under high vacuum. Yield: $95 \%$.

${ }^{1} \mathrm{H}$ NMR (499 MHz, DMSO- $\left.d_{6}\right) \delta 11.99(\mathrm{~s}, 1 \mathrm{H}), 8.60-8.54(\mathrm{~m}, 4 \mathrm{H}), 8.36(\mathrm{~d}, J=8.0 \mathrm{~Hz}, 2 \mathrm{H}), 8.01(\mathrm{~d}, J=$ $8.1 \mathrm{~Hz}, 2 \mathrm{H}), 7.67(\mathrm{t}, J=7.8 \mathrm{~Hz}, 2 \mathrm{H}), 4.03(\mathrm{t}, J=7.5 \mathrm{~Hz}, 2 \mathrm{H}), 2.25(\mathrm{t}, J=7.3 \mathrm{~Hz}, 2 \mathrm{H}), 1.67$ (p, J= 7.6 Hz, 2H), 1.58 (p, $J=7.6 \mathrm{~Hz}, 2 \mathrm{H}), 1.38(\mathrm{p}, J=7.7 \mathrm{~Hz}, 2 \mathrm{H})$.

${ }^{13} \mathrm{C}$ NMR (126 MHz, DMSO-d6) $\delta$ 174.89, 163.44, 137.04, 134.29, 131.56, 129.52, 128.89, 127.83 , $127.50,126.51,125.01,121.38,120.83,49.06,33.96,27.73,26.54,24.70$.

HRMS (ESI-TOF-MS): Expected $\mathrm{m} / \mathrm{z}$ : (435.1478), Observed $\mathrm{m} / \mathrm{z}$ : $\left(436.1543, \mathrm{M}^{+} \mathrm{H}^{+}\right)$

\section{Single Crystal Structure of 1}

Single crystals of $\mathrm{C}_{28} \mathrm{H}_{21} \mathrm{NO}_{4} 1$ were submitted. Crystals were grown from the aging of a solution used for cyclic voltammetry. 1 ( 2 $\mathrm{mg}$ ) was dissolved in DMSO (2 $\mathrm{ml})$ in small vial with tetrabutylammonium hexafluorophosphate $(100 \mathrm{mM})$ and ferrocene $(1 \mathrm{mM})$. After several months at room temperature a suitable crystal had grown and was selected and mounted on a MiTeGen holder in Paratone oil on a Kappa Apex 2 diffractometer. The crystal was kept at $100 \mathrm{~K}$ during data collection. Using Olex2 [1], the structure was solved with the ShelXT [2] structure solution program using Intrinsic Phasing and refined with the ShelXL [3] refinement package using Least Squares minimization.

Crystal Data for $\mathrm{C}_{28} \mathrm{H}_{21} \mathrm{NO}_{4}(M=513.58)$ : triclinic, space group P-1 (no. 2), $a=8.6739(4) \AA$, $b=8.6758(4) \AA, \quad c=17.3880(8) \AA, \alpha=95.459(2)^{\circ}, \quad \beta=95.795(2)^{\circ}, \quad \gamma=112.445(2)^{\circ}, \quad V=$ $1190.41(10) \AA^{3}, Z=2, T=100 \mathrm{~K}, \mu(\mathrm{CuK \alpha})=1.576 \mathrm{~mm}^{-1}$, Dcalc $=1.433 \mathrm{~g} / \mathrm{mm}^{3}, 13528$ reflections measured $(5.17 \leq 2 \Theta \leq 135.35), 4240$ unique $\left(R_{\text {int }}=0.0256, R_{\text {sigma }}=0.0260\right)$ which were used in all calculations. The final $R_{1}$ was $0.0353(\mathrm{I}>2 \sigma(\mathrm{I}))$ and $w R_{2}$ was 0.0997 (all data).

CCDC number: 1817935 


\section{Synthesis of $\mathrm{Na}_{2}\left[\mathrm{Mo}_{3} \mathrm{~S}_{13}\right] \bullet 5 \mathrm{H}_{2} \mathrm{O}$}

The procedure from Kibsgaard et al. ${ }^{2}$ was modified as follows: to $7.692 \mathrm{ml}$ of ammonium sulfide was added $0.5 \mathrm{~g}$ of elemental sulfur. The mixture was agitated and sonicated until all the sulfur dissolved, yielding a bright orange solution. In a separate vial, $1 \mathrm{~g}$ of $\mathrm{Mo}_{7} \mathrm{O}_{24} \bullet 4 \mathrm{H}_{2} \mathrm{O}\left(\mathrm{NH}_{4}\right)_{6}$ was dissolved in $5.1 \mathrm{~mL}$ of water. The molybdenum solution was then added to the sulfur solution resulting in a color change to a deep red. The flask containing this mixture was then sealed and heated at $90^{\circ} \mathrm{C}$ for 5 days. Note: make sure the flask is properly sealed, evaporation of water during heating will result in formation of impurities. After 5 days, the dark red crystals were filtered, washed with water and ethanol, and then transferred to a flask containing $100 \mathrm{~mL}$ of toluene. The toluene was brought to a boil and left for 1 hour. After cooling, the crystals were filtered, washed with fresh toluene $(200 \mathrm{~mL})$, and finally left to dry under vacuum overnight. The crystals were then filtered and dried under vacuum. The crystals $(0.5 \mathrm{~g})$ were then added to $10 \mathrm{~mL}$ of $1 \% \mathrm{NaOH}_{\text {aq }}$ under nitrogen and allowed to stir for 2 hours yielding a deep red solution ${ }^{3}$. The solution was then poured into a $100 \mathrm{~mL}$ of $10 \% \mathrm{NaCl}_{\text {aq }}$ and left overnight until and red/orange precipitate had formed. The precipitate was then filtered and washed with IPA, ether, and finally dried on a vacuum line. The material was stored under argon in a $-20^{\circ} \mathrm{C}$ freezer until use.

\section{Sample Preparation and Annealing Procedure}

1 was first solubilized in a mixture of 3:1 $\mathrm{DCM} / \mathrm{MeOH}(\mathrm{v} / \mathrm{v})$ and transferred to preweighed vials, followed by evaporation in air and to dryness under vacuum. Water and $\mathrm{NaOH}$ (1 eq per 1, using $4 \mathrm{M} \mathrm{NaOH}_{\text {aq }}$ ) was added and the film was sonicated until a deep red solution was obtained (11.5 mM). Solutions were then diluted 5:1 with $\mathrm{NaClaq}_{\mathrm{aq}}(300 \mathrm{mM})$ with vortexing, causing the solution color to lighten which indicates nanostructure crystallization. Control supramolecular polymer samples were left on the bench top and received no further treatment. Extra-large supramolecular polymer samples were synthesized by placing the control sample in a $95^{\circ} \mathrm{C}$ water bath for 1 hour, after which the bath was turned off and the sample slowly cooled over the next hour before being removed. Samples were then vortexed briefly to break apart large aggregates which formed during annealing.

For $\mathrm{pH}$-dependence study, 1 was dissolved into $11.5 \mathrm{mM}$ aqueous solution with an equimolar $\mathrm{NaOH}$. The solution was then either mixed with either water or $300 \mathrm{mM} \mathrm{NaClaq}$ in $5: 1$ volumetric ratio to create $9.6 \mathrm{mM}$ aqueous solution of 1 with equimolar $\mathrm{NaOH}$ in water or in 50 $\mathrm{mM} \mathrm{NaCl} \mathrm{aq}_{\text {. }} 50 \mathrm{uL}$ each of the solution was mixed with varying amounts of $50 \mathrm{mM} \mathrm{HCl}_{\mathrm{aq}}$ and the $\mathrm{pH}$ was measured using a Fisher Scientific accumet micro glass pH electrode. Thermal 
annealing of these solutions were performed in identical conditions as described above, followed by $\mathrm{pH}$ measurements. Samples were aliquoted for UV-Vis spectroscopy, X-ray scattering, and CLSM before and after annealing.

\section{Atomic force microscopy (AFM)}

AFM characterization was performed using a Bruker Dimension ICON atomic force microscope (Bruker Co.) at ambient conditions. Tapping mode was used with single-beam silicon cantilevers with a nominal oscillation frequency of $300 \mathrm{kHz}$. Supramolecular polymer solutions of 1 (4.8 $\mathrm{mM}$ in $50 \mathrm{mM} \mathrm{NaCl}$ aq) were spin coated $(10 \mu \mathrm{L})$ on freshly cleaved mica at $2000 \mathrm{rpm}$.

\section{Ultraviolet - Visible (UV-Vis) Absorption Spectroscopy}

UV-Vis absorption spectroscopy on solutions of 1 (9.6 $\mathrm{mM}$ in $50 \mathrm{mM} \mathrm{NaCl}_{\mathrm{aq}}$ ) was performed in a $0.05 \mathrm{~mm}$ path length, closed demountable quartz spectrophotometer cell (Starna Cells) using an Ocean Optics QEPro Spectrophotometer equipped with a DH-2000-Bal lamp and qpod 2e temperature control sample chamber. Gel absorption spectra were obtained using a Thermo Scientific Nanodrop 1000 Spectrophotometer. VT UV-Vis absorbance spectroscopy was performed in $0.1 \mathrm{~mm}$ path length flow cuvette (Starna Cells, 584,4-Q-0.1) using an Ocean Optics QEPro Spectrophotometer equipped with a DH-2000-Bal lamp and qpod 2e temperature control sample chamber. Solutions of $1(9.6 \mathrm{mM}$ in $50 \mathrm{mM} \mathrm{NaCl} \mathrm{aq})$ was heated and cooled at $1^{\circ} \mathrm{C} / \mathrm{min}$, while collecting full spectra every minute.

Additional UV-Vis absorption spectroscopy upon addition of $\mathrm{HCl}_{\mathrm{aq}}$ was performed on a ThermoFisher NanoDrop ND-1000 spectrophotometer with a path length of $0.1 \mathrm{~mm}$. Samples were vortexed before being applied on the measurement pedestal.

\section{Small Angle X-Ray Scattering (SAXS) / Wide Angle X-ray Scattering (WAXS)}

Solution X-ray scattering measurements were performed at Beamline 5-ID-D in the DuPont-Northwestern-Dow Collaborative Access team (DND-CAT) Synchrotron Research Center at the Advanced Photon Source, Argonne National Laboratory ${ }^{4}$. X-ray energy of $17 \mathrm{keV}$ for room temperature measurements and $10 \mathrm{keV}$ for variable temperature (VT) measurements were selected using a double-crystal monochromator. The scattering vector $q$ is defined as

$$
q=(4 \pi / \lambda) \sin \theta
$$

where $2 \theta$ is the total scattering angle and $\lambda$ is the X-ray wavelength. Samples were oscillated with a syringe pump during exposure to prevent beam damage. 2D to 1D data reduction was 
performed by GSAS-II software. ${ }^{5}$ Background samples containing water or $50 \mathrm{mM} \mathrm{NaCl}$ aq were also collected to perform background subtraction.

For VT measurements, a solution of 1 (9.6 mM in $50 \mathrm{mM} \mathrm{NaCl}$ aq $)$ was annealed inside the vacuum capillary using the following method. Starting at $25^{\circ} \mathrm{C}$, the solution was heated in $5^{\circ} \mathrm{C}$ steps each. The $1 \mathrm{~min}$ heating segment was followed by a 1 min equilibration segment and subsequent data acquisition. Once the solution reached $90^{\circ} \mathrm{C}$, the solution temperature was held for 10 minutes, followed by cooling using the same step method used during heating. During data collecting the sample was oscillated inside the capillary to minimize any beam damage to the sample. Both empty and water-filled vacuum capillary scattering data were recorded with the same VT protocol to ensure appropriate background subtraction. We note that due to the slight temperature-induced drift in the capillary position, signal subtraction of the quartz and water led to fluctuation in baseline for the WAXS traces. The Bragg peaks and the $\pi-$ $\pi$ interaction signature were still visible, however, and we thus show the raw result of the subtraction in Figure 2C.

Additional solution $\mathrm{X}$-ray scattering measurements for $\mathrm{pH}$-dependence study were performed at the same beamline with the X-ray energy of $17 \mathrm{keV}$. Samples were placed in home-built sample cells comprising of two $30 \mu \mathrm{m}$ thick AS32eco ultrathin glass (Schott AG) as window materials, attached to both sides of a $2.0 \mathrm{~mm}$ thick acrylic plate using 9474LE doublestick sheets (3M) as adhesives. The acrylic plates and the double-stick sheets were laser-cut to form sample cells with $6 \mathrm{~mm}$ height and $3 \mathrm{~mm}$ width. The sealed samples were then mounted on a translational stage at the beamline. Background samples containing water or $50 \mathrm{mM} \mathrm{NaCl} \mathrm{aq}$ were also collected to perform background subtraction.

\section{Grazing Incidence X-ray Scattering (GIXS)}

GIXS data was collected at Beamline 8-ID-E in the Advanced Photon Source at Argonne National Laboratory. Samples were prepared by drop casting $40 \mu \mathrm{L}$ of supramolecular polymer solutions of 1 ( $9.6 \mathrm{mM}$ in $50 \mathrm{mM} \mathrm{NaCl}_{\mathrm{aq}}$ ) onto a clean glass substrate. The solutions were allowed to dry in air overnight. The beam energy was $10.915 \mathrm{keV}$, sample-to-detector distance was $228.165 \mathrm{~mm}$, and the incident angle was $0.14^{\circ}$. $2 \mathrm{D}$ scattering patterns were recorded using a Pilatus $1 \mathrm{M}$ detector. 2D data visualization and $1 \mathrm{D}$ line-cut data reduction were performed using GIXSGUI ${ }^{16}$.

\section{Unit cell and molecular orientation determination from X-ray scattering data}


The WAXS peak positions were used to determine the lattice parameters for the 2D oblique unit cell. To subtract background for GIXS line cuts, polynomials were fitted segmentwise to the shoulders of peaks to produce a background function that was subtracted from each of the data points. This background subtracted data are shown in Figure S7A and B. Since the fused rings have more than 2.5 times the number of electrons as the chains, the molecule 1 was modeled as an orthorhombic slab of uniform density with a rod representing the carboxypentyl chain attached at a right angle to the center of its upper edge (Figure S6). Slabs were initially oriented with their longest dimension approximately along the z-axis, perpendicular to the plane of the sheet, and with a free rotational angle about this axis. The rod sizes were fixed so that the projection on $x y$ plane was $4.8 \times 1.8 \AA$ rectangle when the slab is strictly perpendicular. Varying projected sizes of the slab itself on xy plane implicitly accounts for the tilts of the molecule with respect to $z$ axis (Figure S7B). The basis of the lattice consists of four molecules. Molecules, aligned along the side $b$, were assigned equal rotational angle to ensure $\pi-\pi$ parallel stacking. The WAXS scattering pattern was simulated by the scattering theory for randomly oriented 2D structures in solution which accounts for asymmetric line-shape of the peaks. This model-based scattering intensity was fitted by the Levenberg-Marquardt algorithm to the background subtracted WAXS experimental data to extract the rotational angles and slab projected widths best reproducing the relative intensities and line shapes of the peaks ${ }^{7-9}$ (see Figure S7). The obtained $9.0 \AA$ A projected widths indicate $30^{\circ}$ declination with respect to the normal to the nanostructures and only negligible tilt towards side b. (Figure S7B, D)

\section{Transmission electron microscopy (TEM)}

TEM imaging was performed on a JEOL 1230 microscope operating at $100 \mathrm{kV}$ and equipped with a Gatan 831 CCD camera. During imaging the smallest condenser aperture, middle objective and selected area apertures were used. A small spot size ( ${ }^{\text {nd }}$ smallest) was used to further reduced total electron intensity to the sample. The images were calibrated for rotation between real space images and diffraction patterns using a molybdenum oxide standard (Electron Microscopy Sciences, Cat \# 80046), and diffraction images were calibrated for reciprocal space scales using evaporated thallous chloride standard material (Electron Microscopy Sciences, Cat. \# 80045). Here we followed the convention for representing the scattering vector as $s$, defined as

$$
s=(2 / \lambda) \sin \theta
$$

where $2 \theta$ is the total scattering angle and $\lambda$ is the de Broglie wavelength for electron beam. 
Samples were prepared by placing an $8 \mu \mathrm{L}$ droplet of supramolecular polymer solutions of $1(0.96 \mathrm{mM}$ in $50 \mathrm{mM} \mathrm{NaClaq}$ ) on the carbon side of TEM grid (CF300-Cu, Electron Microscopy Science). The solution was allowed to rest for 1 minute before being wicked away and allowed to dry for another 3 minutes. The same method was then used for a wash step with water, a staining step with uranyl acetate (1 wt\%), and final wash step with water.

Due to the beam sensitivity of the supramolecular polymers, the following method was employed to mitigate beam damage. First, the TEM was aligned for diffraction imaging using the diffraction focus knob, and the direct beam blocker was inserted. The sample was then searched in diffraction mode until a region containing a pattern from a single supramolecular polymers was found. An image with $10 \mathrm{sec}$ exposure time was immediately recorded. After collection it was observed that the diffraction spots had begun to fade and would completely disappear after about 30 seconds, but the overall ribbon-like morphology remained intact. Two bright field images were then collected with 2 sec exposures each, one with the SA aperture and one without.

\section{Confocal laser scanning microscopy (CLSM)}

High resolution confocal laser scanning microscopy (CLSM) of the supramolecular polymers of 1 was performed either on a Leica TCS SP 5 confocal microscope using an HCX Plan Apo CS 100x oil-immersion objective or on a Nikon A1R confocal microscope using Plan Apo VC 60x oil immersion objective. For Leica TCS SP5, the excitation wavelength was 561 $\mathrm{nm}$, and the HyD detector was tuned to detect emission between 600 and $700 \mathrm{~nm}$. For Nikon A1R, the excitation wavelength was $561 \mathrm{~nm}$, and a filter cube was used to select $570-620 \mathrm{~nm}$ emission for detection by a photomultiplier tube.

VT-confocal imaging and fluorescence recovery after photobleaching (FRAP) experiments were performed on a Nikon A1R confocal microscope using Nikon Plan Apo VC 20x air objective and Plan Apo VC 60x oil immersion objective, respectively, using the same optical configuration for excitation and emission as described above. The solution of 1 (9.6 mM in $50 \mathrm{mM} \mathrm{NaClaq}_{\text {) }}$ was sealed in a square crosssection glass capillary (Vitrocom) with a UVsensitive epoxy, and was placed in a custom-built VT stage for CLSM. The sample was heated from $25^{\circ} \mathrm{C}$ to $95^{\circ} \mathrm{C}$ at $5^{\circ} \mathrm{C} / \mathrm{min}$, then held at $95^{\circ} \mathrm{C}$ for $30 \mathrm{~min}$. The sample was then cooled to $25^{\circ} \mathrm{C}$ at $1^{\circ} \mathrm{C} / \mathrm{min}$. The fluorescence intensity decrease at elevated temperatures is attributed to both the decrease in quantum efficiency of $\mathbf{1}$ due to the activation of non-radiative decay pathway from the excited state, as well as the loss of crystallinity. We also observed photobleaching effect toward the end of the acquisition period, which was highlighted by the 
lower fluorescence intensity in the scanned region post-acquisition.

To create hydrogels of $\mathbf{1}$ for confocal imaging, a custom-made sample cell was fabricated by gluing plastic cones on a glass cover slip using 5 minute epoxy. The plastic cones were made by cutting the top $60 \%$ of 200 uL pipette tips. After the epoxy was cured, supramolecular polymer hydrogels were created by adding $20 \mathrm{uL}$ of the annealed and control solution of 1 (9.6 mM in $50 \mathrm{mM} \mathrm{NaCl} \mathrm{aq}_{\text {) }}$ and $4 \mathrm{uL}$ of PDDA solution (20 wt\%, medium molecular weight, Sigma Aldrich), followed by 172 uL of $0.01 \%$ 8-hydroxypyrene-1,3,6-trisulfonic acid trisodium salt (HPTS) solution in $1.7 \mathrm{M} \mathrm{pH} 4$ ascorbic acid solution $\mathrm{pH}$-balanced by $\mathrm{NaOH}_{\mathrm{aq}}$. The samples were incubated at room temperature for several hours before FRAP measurements were performed. For FRAP experiments, samples were scanned with $485 \mathrm{~nm}$ (1\% power setting) and $562 \mathrm{~nm}$ (5\% power setting) excitation wavelengths for $10 \mathrm{sec}$ at 1 frame/s with the scan area of $200 \mu \mathrm{m} \times 200 \mu \mathrm{m}$. Then, the $485 \mathrm{~nm}$ laser was used at $100 \%$ to photobleach a region of $30 \mu \mathrm{m} \times 30 \mu \mathrm{m}$ in the middle of the field of view over $4 \mathrm{sec}$. The fluorescence recovery was subsequently observed using the same probe setting as before the photobleaching. The average intensity in the photobleached region was fitted to a one-component exponential decay function using FRAP Profiler v2 macro for Fiji ${ }^{10}$, developed by Dr. Jeff Hardin at the University of Wisconsin-Madison (http://worms.zoology.wisc.edu/research/4d/4d.html\#frap).

\section{Scanning electron microscopy (SEM)}

Supramolecular polymer hydrogels were dehydrated by incubating in a series of ethanol solutions of increasing concentration from 30-100\% of 200 proof ethanol (Decon Laboratories, Inc). Ethanol was then removed by critical point drying (Tousimis Samdri-795). The dehydrated supramolecular polymer samples were subsequently mounted on stubs using carbon glue and coated with approximately $16 \mathrm{~nm}$ of osmium (Filgen, OPC-60A) to create a conductive sample surface for imaging. All SEM images of the supramolecular polymers were taken using a Hitachi SU8030 instrument with an accelerating voltage of $2 \mathrm{kV}$.

\section{Quantum efficiency measurements}

Quantum efficiency (QE) measurements were carried out by preparing photocatalytic proton reduction samples as described above. Samples where then irradiated at 447, 505, and $567 \mathrm{~nm}$ with LEDs purchased from LuxeonStar LED. The specifications on the three LEDs are as follows. Royal-blue $447.5 \mathrm{~nm}$ rebel ES LED on a SinkPAd-II $23 \mathrm{~mm}$ round base $4120 \mathrm{~mW}$ at 700 mA. Cyan $505 \mathrm{~nm}$ rebel ES LED on a SinkPAd-II $23 \mathrm{~mm}$ round base $488 \mathrm{Im}$ at $700 \mathrm{~mA}$. Lime 567 
$\mathrm{nm}$ rebel ES LED on a SinkPAd-II $23 \mathrm{~mm}$ round base $1252 \mathrm{Im}$ at $700 \mathrm{~mA}$. Light from the LEDs was passed through a Schott (A21045) quad neck fiber optic cable so that four samples could be irradiated at once. Light intensity was measured using a Newport 843-R handheld power meter equipped with a 919P-030-18 general purpose thermopile sensor. Four experiments were run at each wavelength for each condition and the QE was determined using the following equation:

$$
Q E(\%)=\frac{n\left(H_{2}\right) * N_{A} * h * c * 2}{\lambda * t * p} * 100
$$

where $n\left(H_{2}\right)=$ moles of photo-generated $\mathrm{H}_{2}$ [mol], $N_{A}=$ Avogadro's constant [mol ${ }^{-1}$ ], $h=$ Planck's constant [ $\mathrm{J} \mathrm{s}$ ], $c=$ speed of light [ $\left.\mathrm{m} \mathrm{s}^{-1}\right], \lambda=$ wavelength [m], $t=$ irradiation time [s], $p=$ power value [watts] defined as the difference in measured power between a blank sample (vial with only water) and a full hydrogen production sample.

\section{Transient Absorption Spectroscopy}

Femtosecond transient absorption spectroscopy (fsTA) experiments were performed using a regeneratively-amplified Ti:sapphire laser system (Tsunami oscillator / Spitfire Pro amplifier, Spectra-Physics) as previously described ${ }^{11-12}$ with the following modification to the probe generation and detection. The UV-vis continuum probe $(\lambda \sim 330-800 \mathrm{~nm})$ was generated by focusing the $\lambda=827 \mathrm{~nm}$ fundamental (100 fs, $2 \mu \mathrm{J})$ into a $3 \mathrm{~mm} \mathrm{CaF}{ }_{2}$ crystal cut along the $<001>$ axis (Newlight Photonics Inc.). The NIR continuum probe $(\lambda \sim 850-1600 \mathrm{~nm})$ was generated by focusing the $\lambda=827 \mathrm{~nm}$ fundamental (100 fs, $3 \mu \mathrm{J}$ ) into a $10 \mathrm{~mm}$ proprietary crystal (Ultrafast Systems, LLC). The probe pulse was split prior to interaction with the sample to provide signal and reference probe pulses which were detected with a customized Helios spectrometer and Helios software (Ultrafast Systems, LLC). The samples were irradiated at $\lambda_{\mathrm{ex}}$ $=447,505$ or $567 \mathrm{~nm}$ with $\sim 110 \mathrm{fs}, 0.4-0.6 \mu \mathrm{J}$ pulses with randomized polarization (DPU-25-A, Thorlabs, Inc) to suppress observation of rotational dynamics. The $\lambda_{\mathrm{ex}}=505$ and $567 \mathrm{~nm}$ excitation pulses were generated with a home-built optical parametric amplifier ${ }^{13}$, and the $\lambda_{\mathrm{ex}}=$ $447 \mathrm{~nm}$ excitation pulse was generated with a commercial non-collinear optical parametric amplifier (TOPAS-White, Light Conversion). Transient spectra were acquired with $3 \mathrm{~s}$ averaging at each time delay point. The instrument response was about $300 \mathrm{fs}$. Aged and annealed samples were prepared in demountable cuvettes with pathlength of $100 \mu \mathrm{m}$ and $\lambda_{\max }=0.51$ and $0.58 \mathrm{OD}$, respectively. The fresh sample was prepared in a demountable cuvette with $50 \mu \mathrm{m}$ and $\lambda_{\max }=0.45 \mathrm{OD}$. The fsTA data were corrected for group delay dispersion, or chirp, and scattered light prior to the analysis using Surface Xplorer (Ultrafast Systems, LLC). 
As the visible absorbance $(600-700 \mathrm{~nm})$ in our supramolecular polymers decays, a broad near-infrared feature increased in intensity, suggesting a cascade of singlet excited state to an excimer-like state is possible (Figure S19,29). In non-crystalline solutions of 1 before the addition of sodium chloride, the excited state lifetime is less than 500 ps, and the visible and near-infrared features decay on similar time scales (Figure S18).

\section{$\mathrm{H}_{2}$ Production Experiments}

Solutions of $1(100 \mu \mathrm{L}, 9.6 \mathrm{mM}$ in $50 \mathrm{mM} \mathrm{NaCl}$ aq) containing extra-large or control supramolecular polymers were first gelled with poly(diallyldimethylammonium chloride) $(20 \mu \mathrm{L}$, $5 \mathrm{wt} \%, 409022-1 \mathrm{~L}$ ) in a $7 \mathrm{ml}$ screw cap vial with a silicone/PTFE septum (Thermo Scientific, Product number TS-13028) and allowed to age for 2 hours. Ascorbic acid solutions (1.7 M, $0.299 \mathrm{~g} / \mathrm{mL}$ ) were adjusted to $\mathrm{pH} 4$ using $4 \mathrm{M} \mathrm{NaOH}_{\mathrm{aq}}$ (measured using a Fisher Scientific Accumet Research AR50 Dual Channel pH/lon/Conductivity Meter, calibrated with pH 4.0 and $\mathrm{pH} 7.0$ standard solutions. $20 \mu \mathrm{L}$ of the $\left[\mathrm{Mo}_{3} \mathrm{~S}_{13}\right]^{2-}$ cluster aqueous solution $(180 \mu \mathrm{M}, 1 \mathrm{mg}$ in $7.5 \mathrm{~mL}$ ) along with $860 \mu \mathrm{L}$ of ascorbic acid solution as a source of protons and sacrificial electrons. Vials were sealed and purged for 15 minutes with argon. Unless otherwise specified, the vials were then illuminated for 18 hours using a Schott DCR III lamp equipped with a $150 \mathrm{~W}$ halogen EKE bulb (output 400 - $700 \mathrm{~nm}$ ) and fiber optic goosenecks. Samples were placed approximately $0.6 \mathrm{~cm}$ from the fiber optic light source. For $\mathrm{H}_{2}$ quantification, a $300 \mu \mathrm{L}$ aliquot was taken from the sample vial $(7.5 \mathrm{~mL}$ headspace) and injected onto a gas chromatograph (Shimadzu GC-2014) equipped with a $5 \AA$ molecular sieve column, argon carrier gas, and a thermal conductivity detector. We noticed that some vials contained pressure due to the gas evolution, but did not consider the pressure buildup in turnover number (TON) calculation. This discrepancy can lead to underestimation of the TON and the turnover frequency (TOF). Eightpoint calibration curves for $\mathrm{H}_{2}$ and $\mathrm{N}_{2}$ were created using a standard gas $\left(7 \% \mathrm{H}_{2}\right.$ balanced with $\mathrm{N}_{2}$ ) and integrated peak areas were used to determine the $\mathrm{H}_{2}$ concentration in the sample headspace at STP. Our results also suggest that electron transfer occurs at the nanostructure "faces" and not at nanostructures "edges". Extra-large supramolecular polymers are composed of $\sim 99.8 \%$ face and $\sim 0.2 \%$ edge area, whereas control supramolecular polymers are $\sim 97.2 \%$ face and $\sim 2.8 \%$ edge. If edges are significantly more active we would expect control nanostructures to produce more $\mathrm{H}_{2}$, which is opposite to the observed trend, thus we speculate that the edges are not the active sites for such photocatalytic reactions.

\section{Nitrogen physisorption experiment}


Nitrogen physisorption experiments were performed on a Micromeritics 3Flex instrument. To generate dry gels of the supramolecular polymers, the supramolecular polymer solutions (9.6 mM in $\left.50 \mathrm{mM} \mathrm{NaCl}_{\mathrm{aq}}\right)$ were gelled with $150 \mathrm{mM} \mathrm{CaCl}_{2 \mathrm{aq}}(5: 1 \mathrm{v} / \mathrm{v})$ added dropwise. They were rested for at least 6 hours, then rinsed in water with a cell strainer (Fisherbrand). The gels were then flash frozen in an aluminum dish floated on liquid nitrogen, then lyophilized. The samples were degassed using the Smart VacPrep instrument (Micromeritics) at $50^{\circ} \mathrm{C}$ overnight. For the sorption experiments, a low pressure does of $0.268 \mathrm{mmol} / \mathrm{g}$ was used, and equilibration intervals of 10-20s were used. Brunauer-Emmett-Teller (BET) specific surface areas were calculated for adsorption data points between $0.09<P / P_{0}<0.30$.

Theoretical specific surface area of the supramolecular polymers were calculated based on an infinite 2D crystal:

$$
A=\frac{2 a b \sin \theta}{m n}
$$

where $A$ is the specific surface area $\left(\mathrm{m}^{2} / \mathrm{g}\right), a, b$ and $\vartheta$ are the unit cell parameters, $m$ is the mass of the molecule and $n$ is the number of molecules within a unit cell. From the unit cell information, we calculate the theoretical specific surface area to be $786 \mathrm{~m}^{2} / \mathrm{g}$, one order of magnitude larger than the measured values (Figure S26). We suspect that the freezing process led to ice templating and overlapping of the supramolecular polymers. 


\section{Supplementary Figures and Tables}

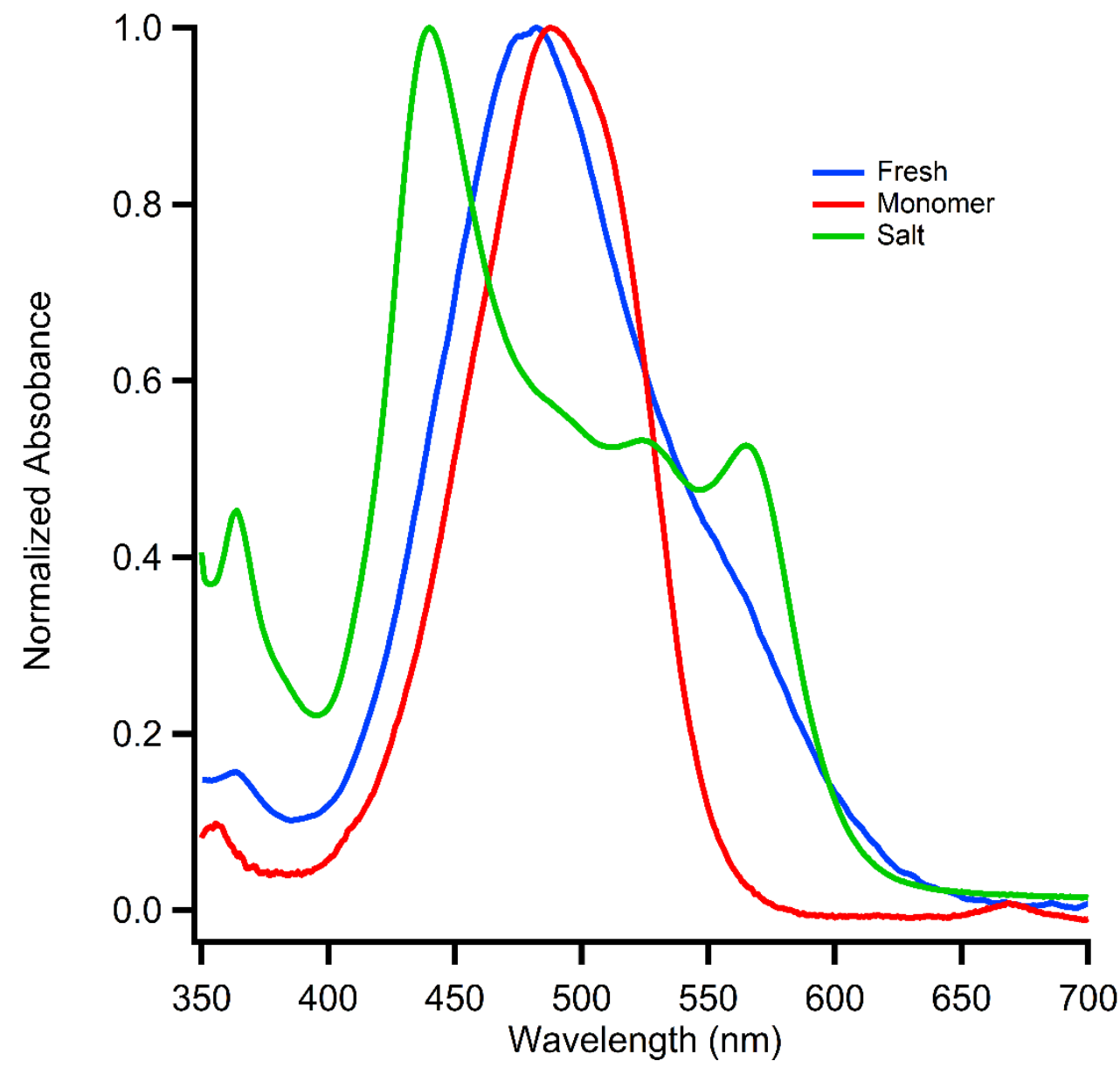

Figure S1: Absorption spectra for monomeric $1(0.38 \mathrm{mM})$ in DMSO (red), freshly dissolved aqueous $1(0.38 \mathrm{mM})$ without added salt (blue) and after the addition of salt (green). 

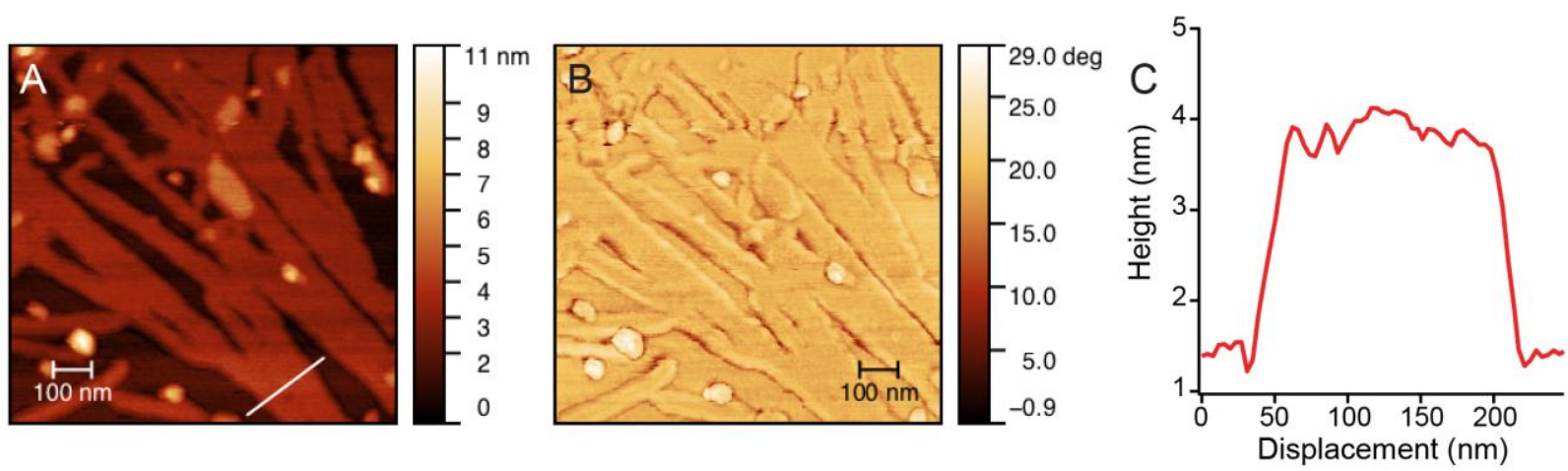

Figure S2: Atomic force microscopy of the control supramolecular polymer of 1 ( $9.6 \mathrm{mM}$ in 50 $\mathrm{mM} \mathrm{NaCl}{ }_{\mathrm{aq}}$ ). (A) Height profile. This image is also shown in Figure 1E. (B) Phase image. (C) Height image line cut.
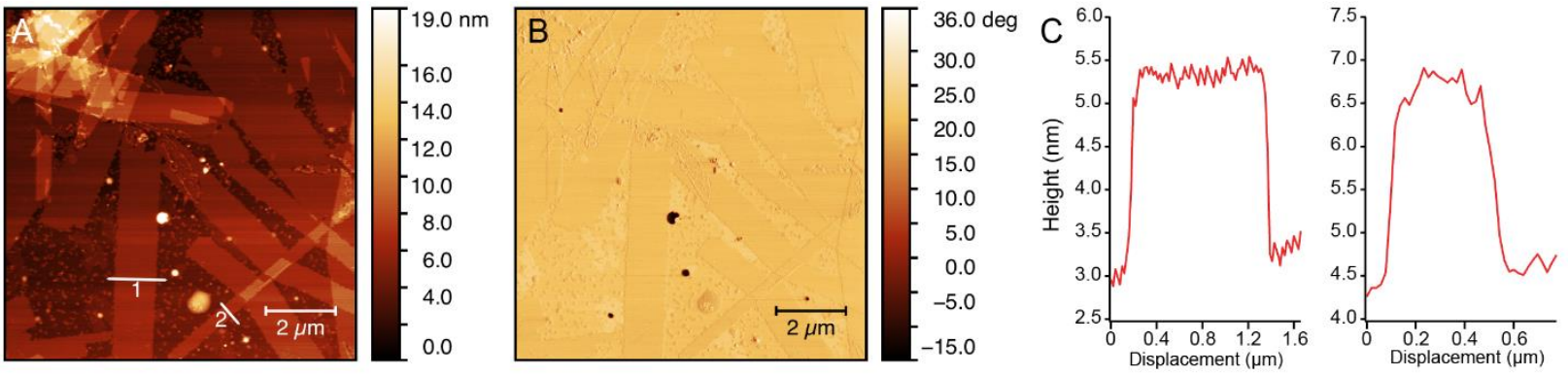

Figure S3: Atomic force microscopy of annealed, extra-large supramolecular polymer of 1 (9.6 $\mathrm{mM}$ in $50 \mathrm{mM} \mathrm{NaCl}{ }_{\text {aq }}$. (A) Height profile. (B) Phase image. (C) Height image line cut.
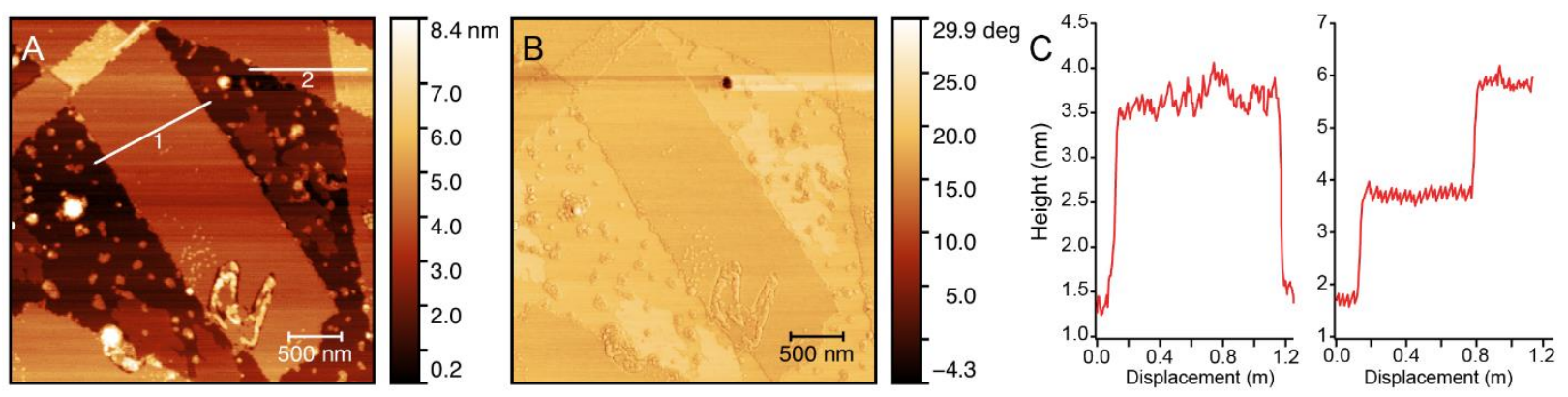

Figure S4: Atomic force microscopy of annealed, extra-large supramolecular polymer of 1 (9.6 $\mathrm{m}$ in $50 \mathrm{mM} \mathrm{NaClaq}$ ). (A) Height profile. This image is also shown in Figure 1F. (B) Phase image. (C) Height image line cut. 

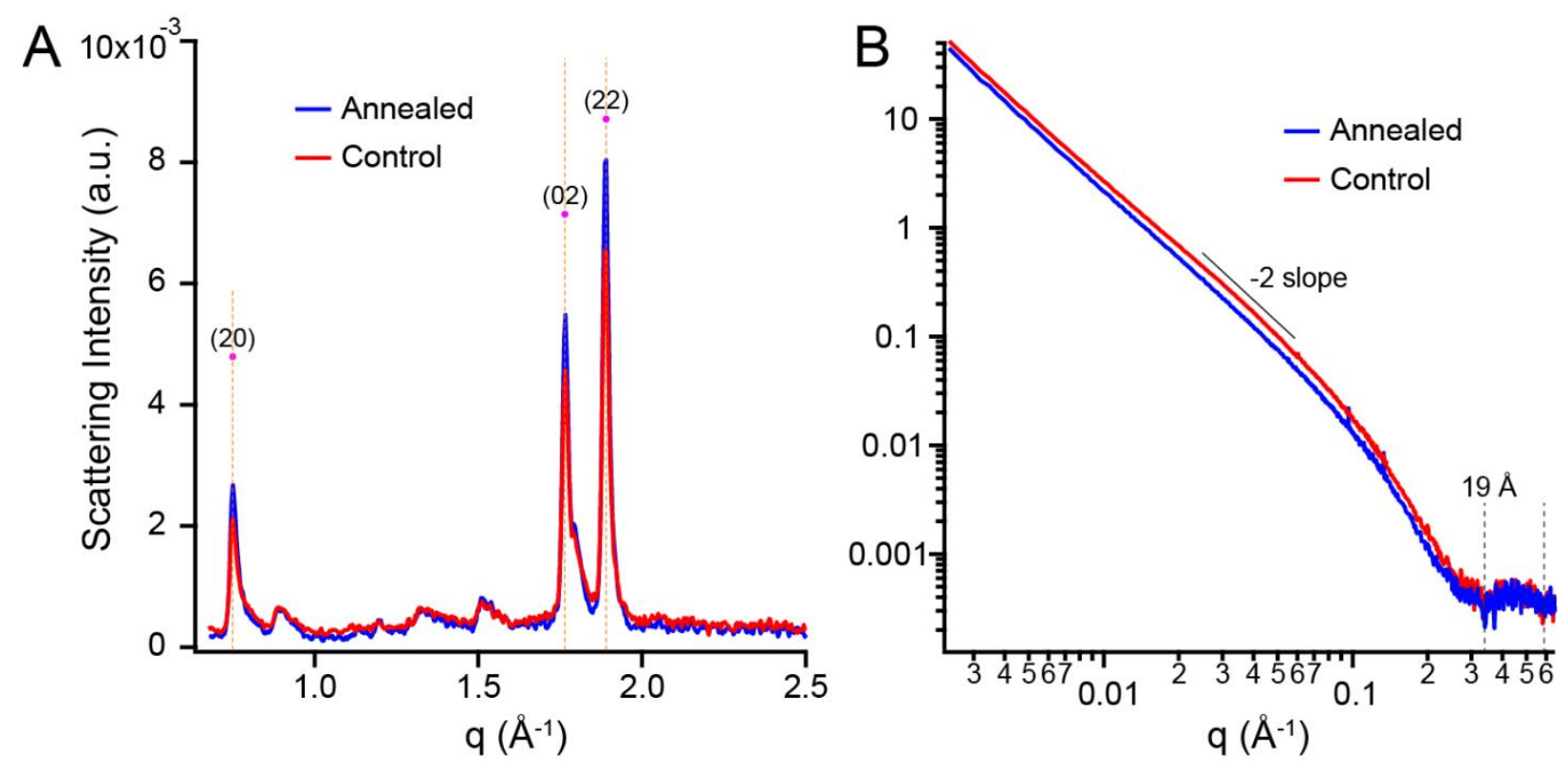

Figure S5: Room temperature solution SAXS/WAXS patterns. (A) Solution WAXS patterns of the supramolecular polymers $(9.6 \mathrm{mM}$ in $50 \mathrm{mM} \mathrm{NaCl} \mathrm{mq})$. The control sample is shown in red, and the annealed sample is shown in blue. (B) Solution SAXS patterns of the supramolecular polymers $(9.6 \mathrm{mM}$ in $50 \mathrm{mM} \mathrm{NaCl}$ aq $)$. The control sample is shown in red, and the annealed sample is shown in blue. 
A

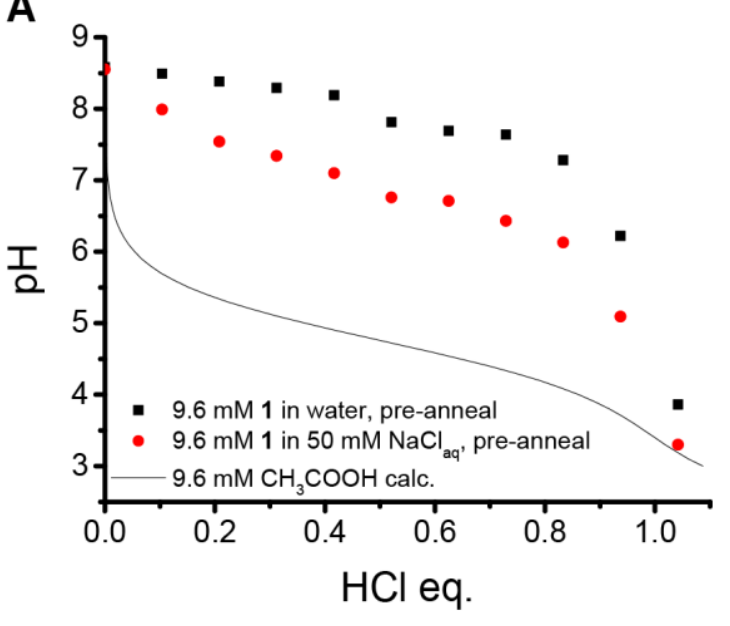

B

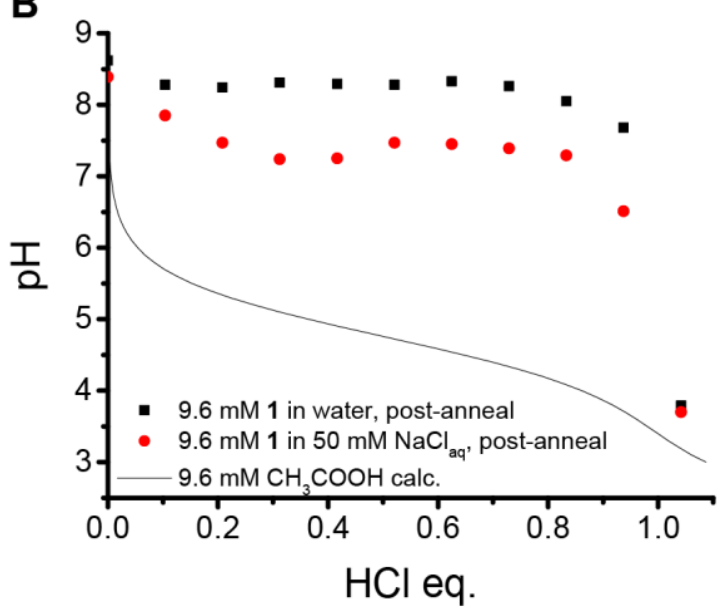

Figure S6: $\mathrm{pH}$ titration curves for solutions of 1.1 was first dissolved into water with an equimolar $\mathrm{NaOH}$. For the samples shown in black squares, varying amount of $\mathrm{HCl}_{\text {aq }}$ were added before $\mathrm{pH}$ measurement. For the samples shown in red circles, $\mathrm{NaCl}_{\mathrm{aq}}$ was added, followed by addition of varying amount of $\mathrm{HCl}_{\text {aq. }}$ (A) $\mathrm{pH}$ values before thermal annealing. (B) $\mathrm{pH}$ values after thermal annealing at $95^{\circ} \mathrm{C}$ for 1 hour. The solid line indicates the calculated titration curve for acetic acid $\left(p \mathrm{~K}_{a}=4.756\right)$. 

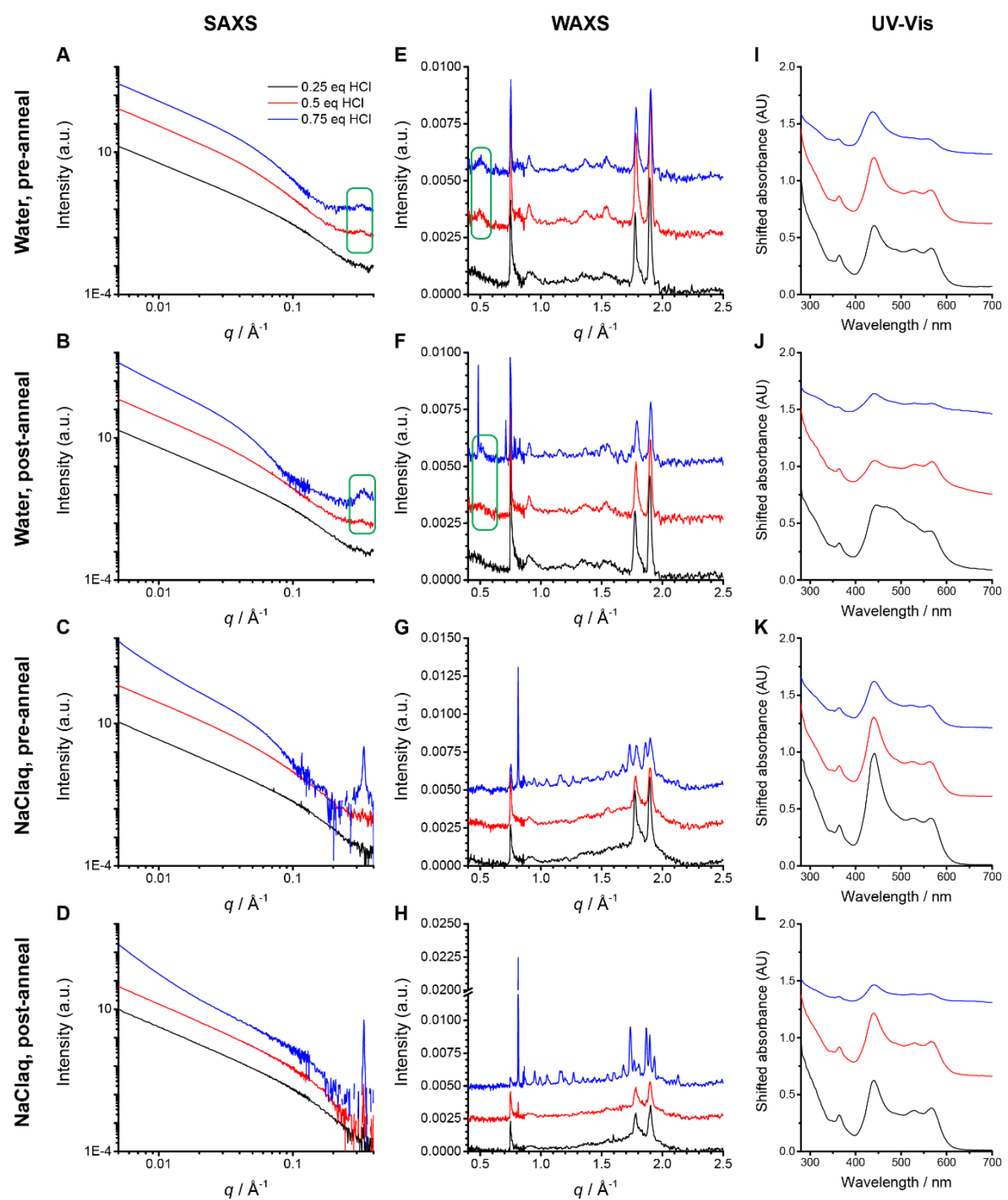

Figure S7: $\mathrm{pH}$-dependent structural characterization of 1. In all cases, 1 was dissolved into water with an equimolar $\mathrm{NaOH}$, then the additional $\mathrm{NaCl}$ and $\mathrm{HCl}$ were added. (A-D) SAXS patterns, (E-H), WAXS patterns and (I-L) UV-Vis spectra. (A, E, I) $9.6 \mathrm{mM} 1$ in $50 \mathrm{mM} \mathrm{NaCl} \mathrm{aq}$ before annealing. (B, F, J) $9.6 \mathrm{mM} 1$ in $50 \mathrm{mM} \mathrm{NaCl}$ aq after annealing. (C, G, K) $9.6 \mathrm{mM} 1$ in water before annealing. (B, F, J) $9.6 \mathrm{mM} 1$ in water after annealing. For each plot, black lines indicate samples with 0.25 equivalence of $\mathrm{HCl}$ added, red lines indicate samples with 0.5 equivalence of $\mathrm{HCl}$ added and blue lines indicate samples with 0.75 equivalence of $\mathrm{HCl}$ added. For SAXS, red and blue curves are shifted $x 10$ and $x 100$ vertically. For WAXS, red and blue curves are shifted $0.0025 \mathrm{~cm}^{-1}$ and $0.005 \mathrm{~cm}^{-1}$ vertically. For UV-Vis, red and blue spectra are shifted $0.6 \mathrm{AU}$ and 1.2 AU vertically. The formation of precipitates for samples with $\mathrm{HCl}$ equivalences of 0.5 and above are visualized by the increase in intensity near the beamstop in SAXS traces, emergence of complex Bragg peaks in WAXS traces as well as the baseline increase caused by scattering in UV-Vis spectra. The broad peak circled in panels A, B, E, F indicate the formation of closely stacked supramolecular polymers. 


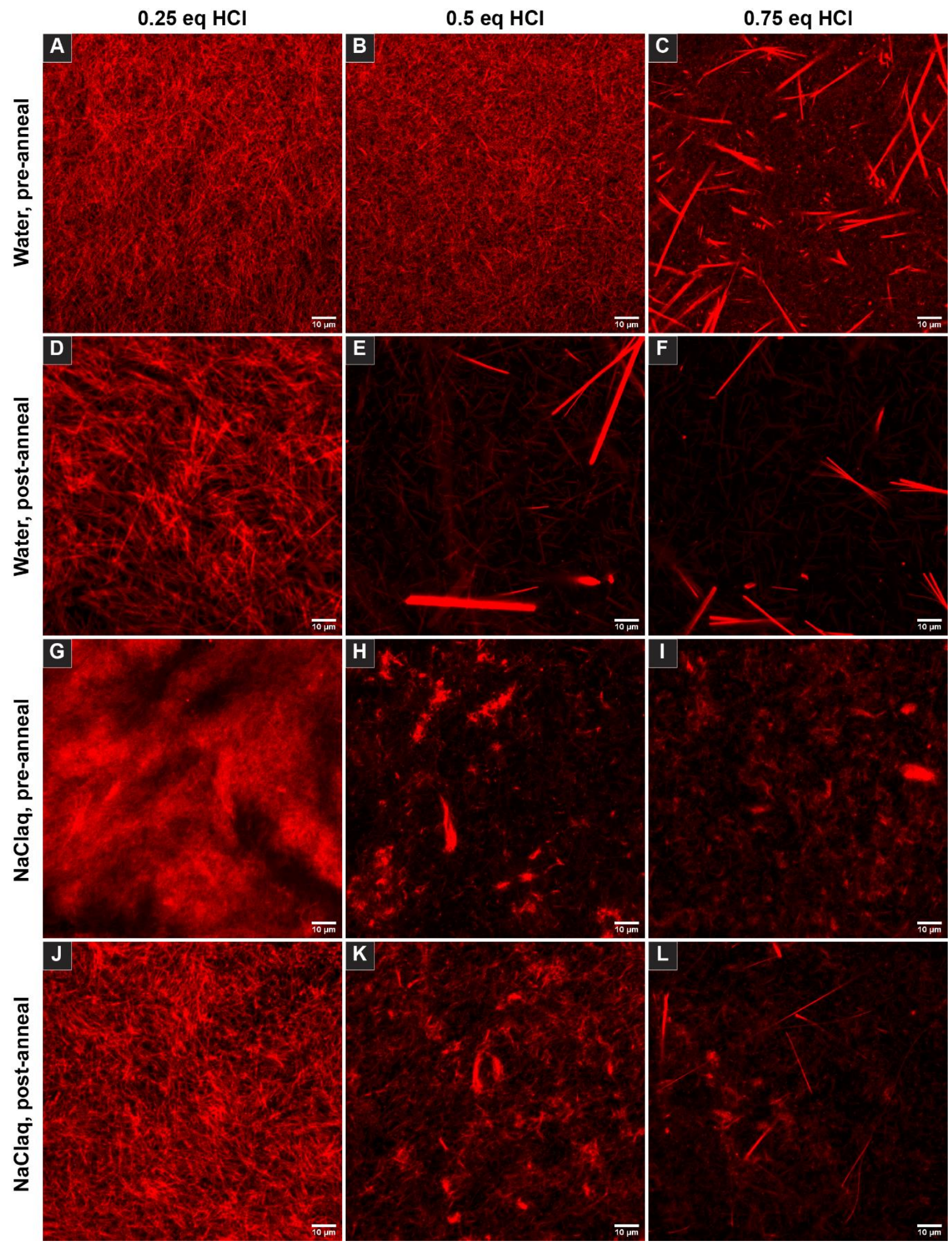

Figure S8: CLSM images of 1 in varying $\mathrm{pH}$. In all cases, $\mathbf{1}$ was dissolved into water with an equimolar $\mathrm{NaOH}$, then the additional $\mathrm{NaCl}$ and $\mathrm{HCl}$ were added. Bright rod-like materials observed in acidic samples correspond to bulk crystalline precipitates. 
A

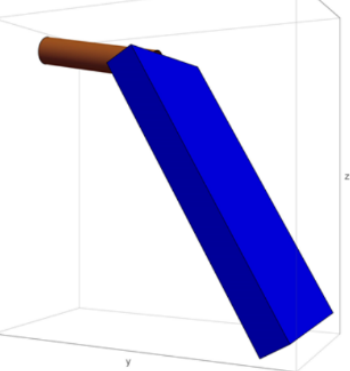

B

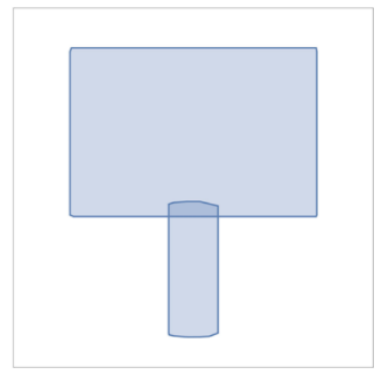

Figure S9: (A) 3D schematic model of the molecule 1. (B) 2D projection of the model onto the plane of the nanosheet.

A
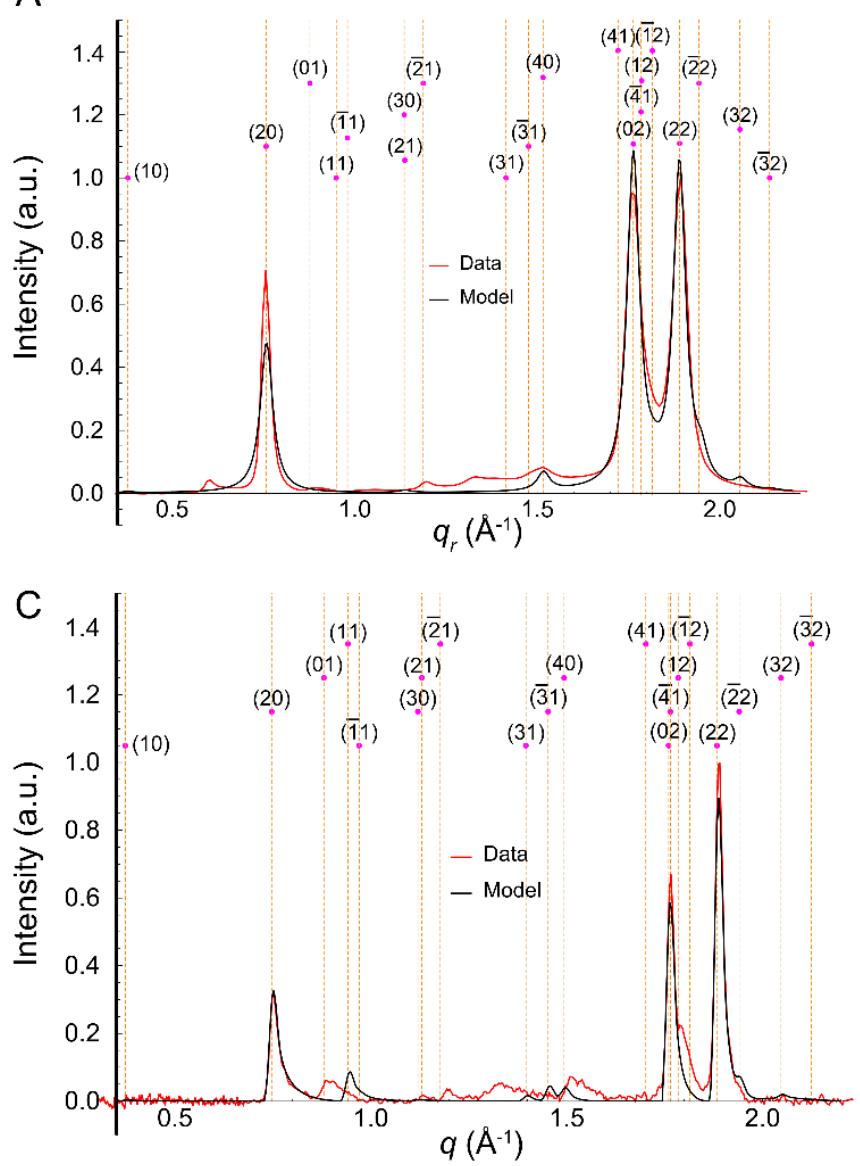

B

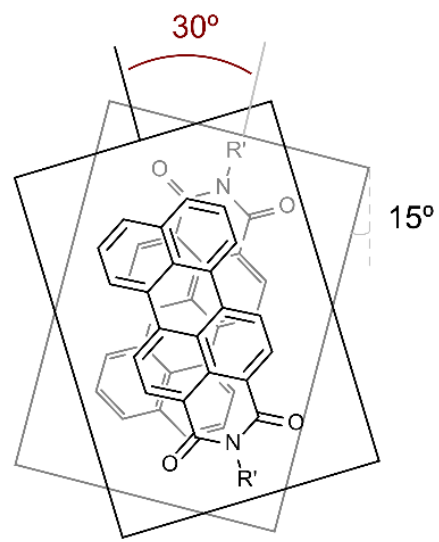

$\mathrm{D}$

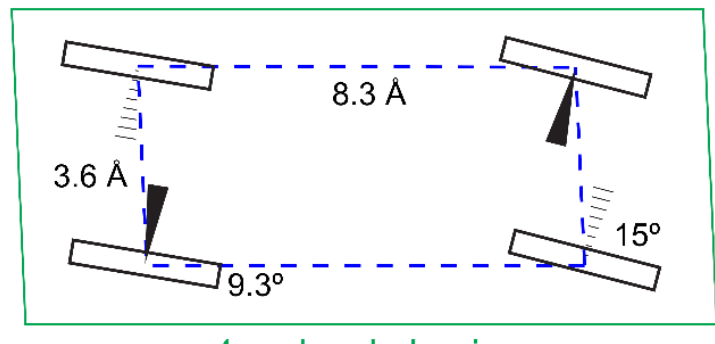

4 molecule basis

Figure S10: (A) Background subtracted GIWAXS data and model fits for 1 in the supramolecular polymers. The model is described by a basis set of 4 molecules that occupy a quadrant of the oblique 2D unit cell (inset of Fig. 3A) with lattice parameters $a$ and $b$ being twice the edge lengths of the basis set parallelogram shown above. The listed $(h k)$ indices are for $a>b$. (B) Deduced declination angle of the perylene slab with respect to the normal to nanosheet plane. For details we refer the readers to ref. 8. (C) Background subtracted solution WAXS data and model fits for supramolecular polymer of 1. (D) The 4 molecule basis quadrant of the oblique 2D unit cell in the supramolecular polymer of 1. 

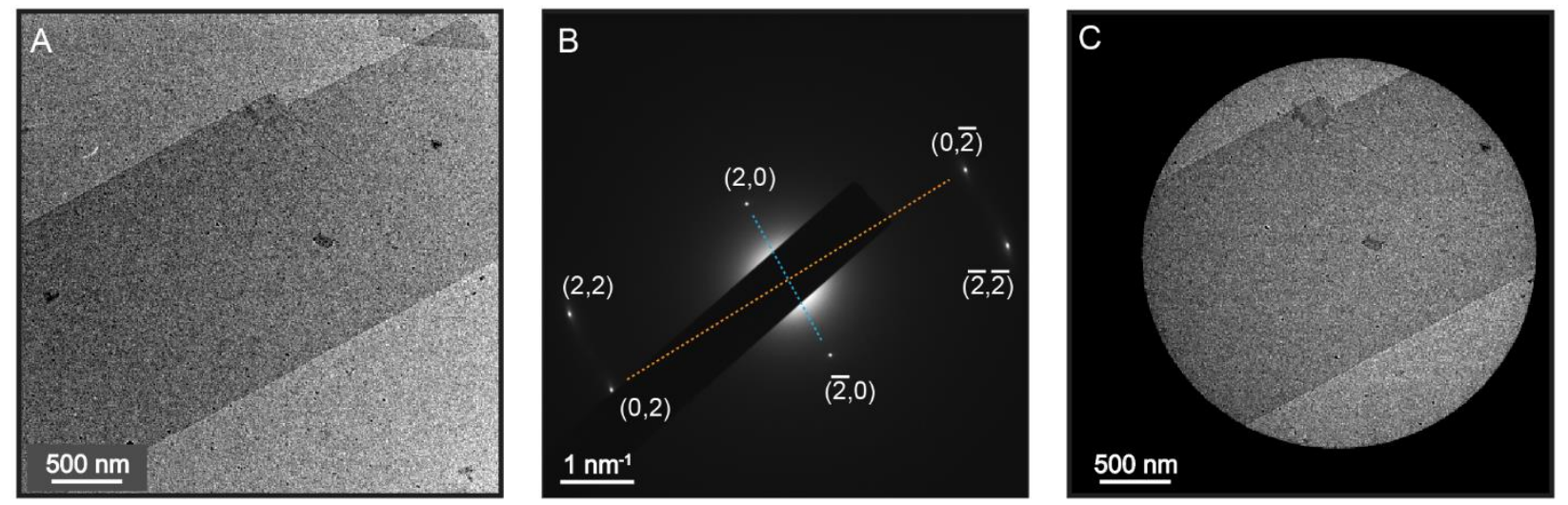

Figure S11: Spot 1. (A) Bright field TEM of annealed, extra-large supramolecular polymer of 1 $(9.6 \mathrm{~m}$ in $50 \mathrm{mM} \mathrm{NaCl}$ aq). (B) Corresponding diffraction pattern. The panels $(A)$ and $(B)$ are shown as Figure $3 \mathrm{~A}$ and $\mathrm{B}$. (C) Selected area aperture size used when collecting diffraction data.
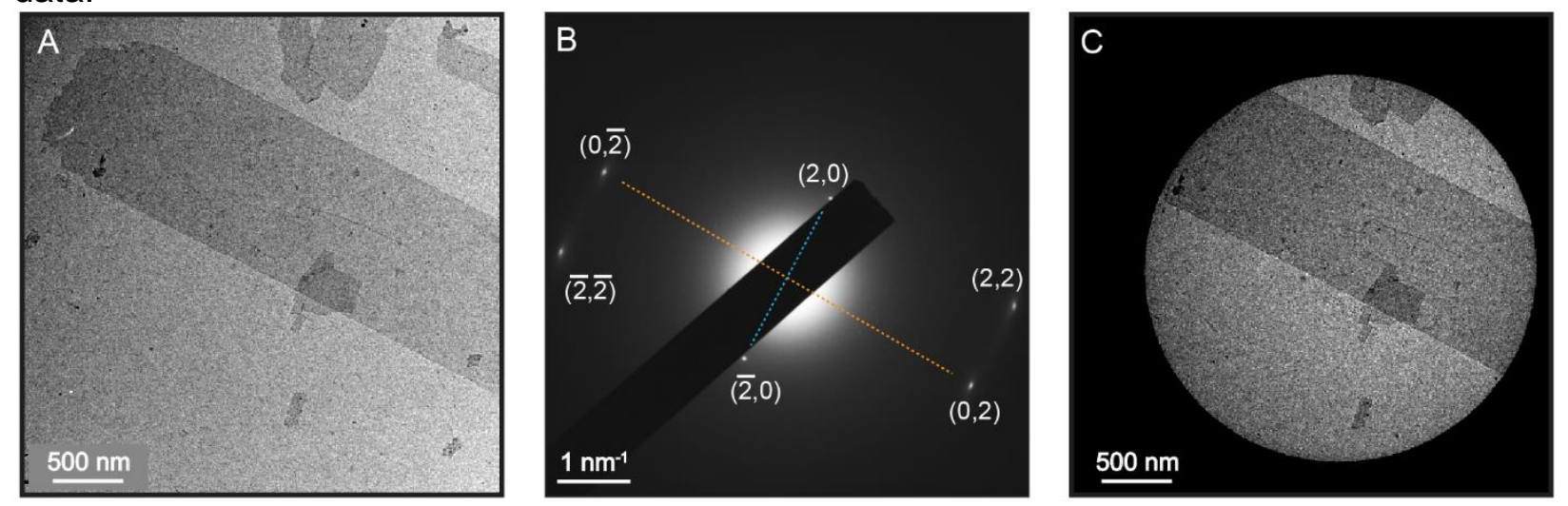

Figure S12: Spot 2. (A) Bright field TEM of annealed, extra-large supramolecular polymer of 1 (9.6 $\mathrm{m}$ in $50 \mathrm{mM} \mathrm{NaCl}_{\mathrm{aq}}$ ) (B) Corresponding diffraction pattern. (C) Selected area aperture size used when collecting diffraction data.
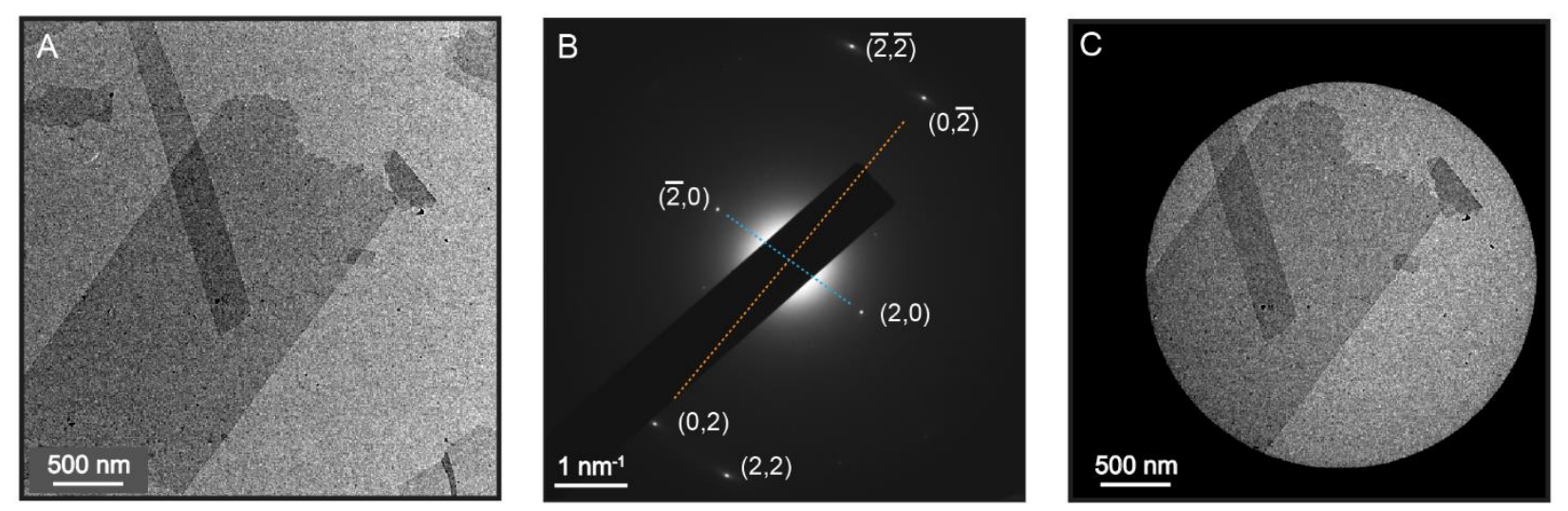

Figure S13: Spot 3. (A) Bright field TEM of annealed, extra-large supramolecular polymer of 1 $(9.6 \mathrm{~m}$ in $50 \mathrm{mM} \mathrm{NaCl}$ aq). (B) Corresponding diffraction pattern. (C) Selected area aperture size used when collecting diffraction data. 

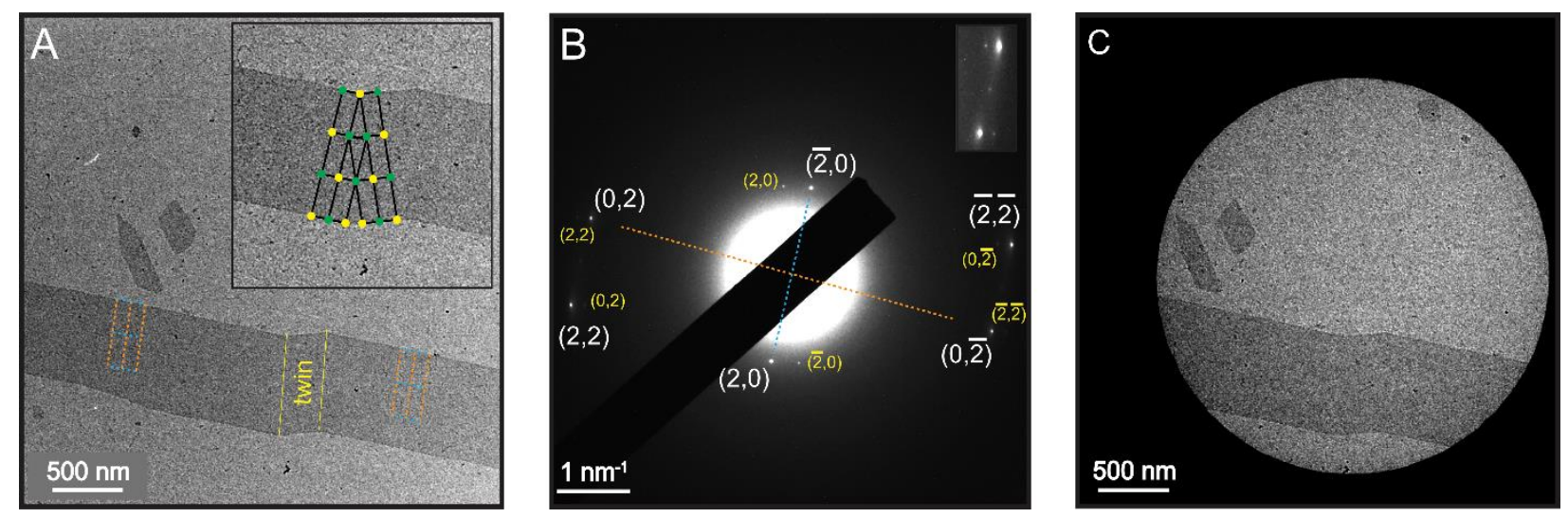

Figure S14: Spot 4. (A) Bright field TEM of annealed, extra-large supramolecular polymer of 1 $(9.6 \mathrm{~m}$ in $50 \mathrm{mM} \mathrm{NaCl}$ aq). (B) Corresponding diffraction pattern. The panels (A) and (B) are shown as Figure $3 \mathrm{C}$ and $\mathrm{D}$. (C) Selected area aperture size used when collecting diffraction data.
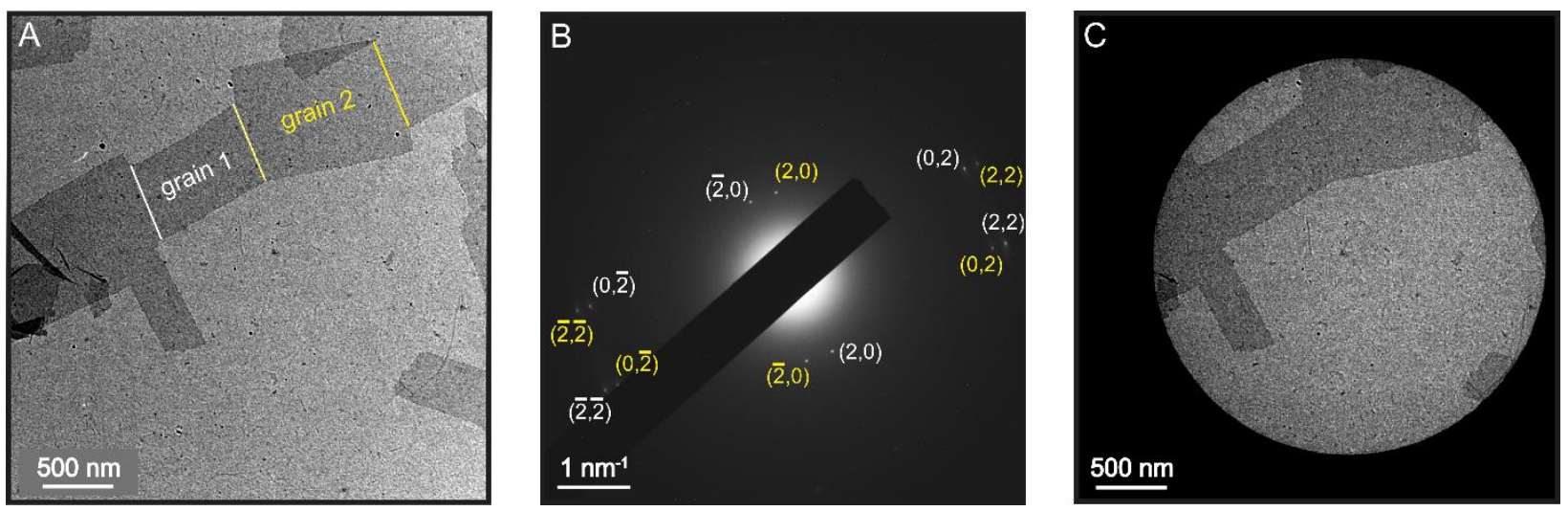

Figure S15: Spot 5. (A) Bright field TEM of annealed, extra-large supramolecular polymer of 1 (9.6 $\mathrm{m}$ in $50 \mathrm{mM} \mathrm{NaCl}$ aq) (B) Corresponding diffraction pattern. (C) Selected area aperture size used when collecting diffraction data.
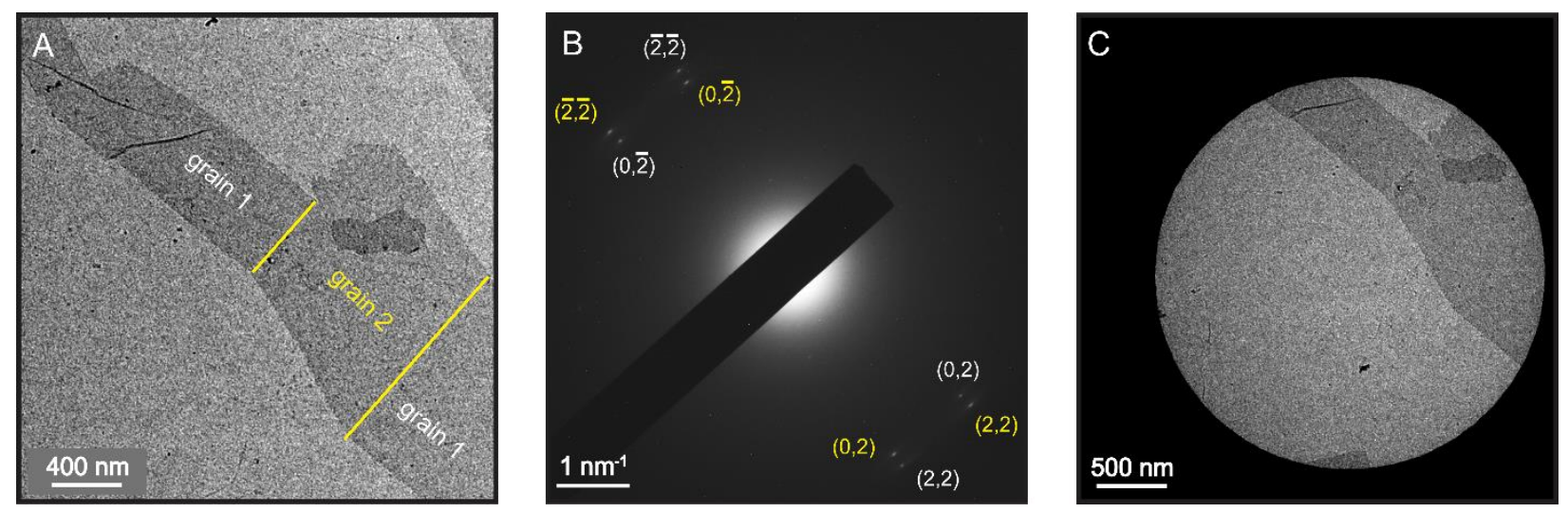

Figure S16: Spot 6. (A) Bright field TEM of annealed, extra-large supramolecular polymer of 1 (9.6 $\mathrm{m}$ in $50 \mathrm{mM} \mathrm{NaCl}$ aq) (B) Corresponding diffraction pattern. (C) Selected area aperture size used when collecting diffraction data. 

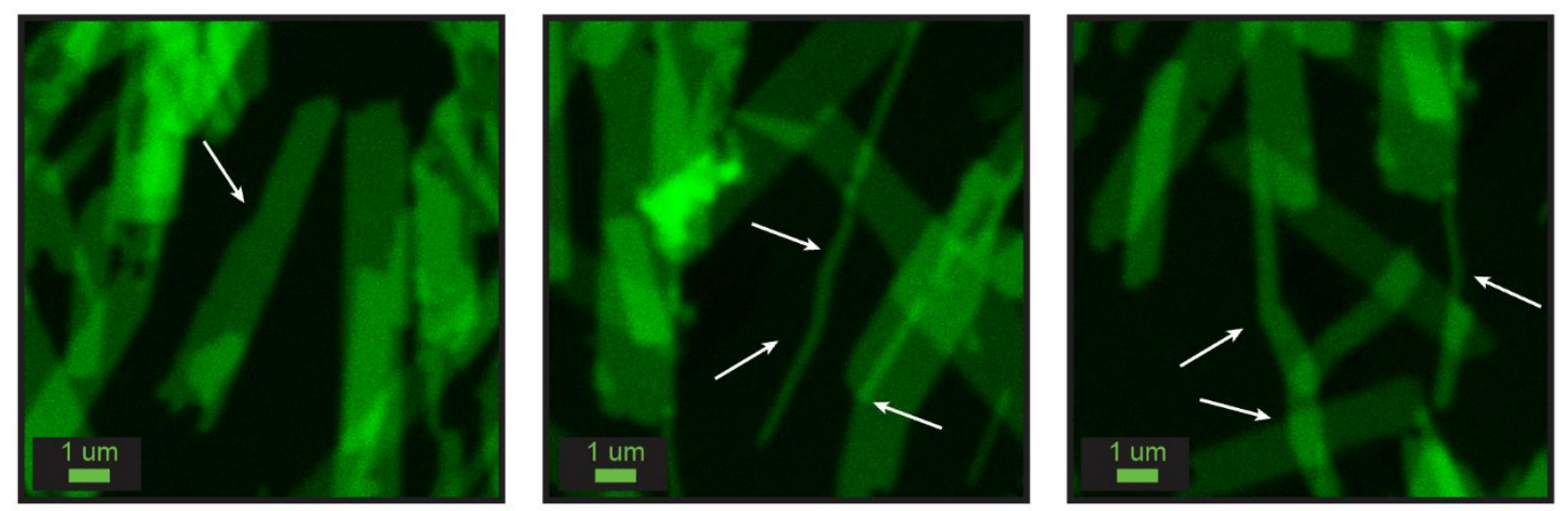

Figure S17: CLSM images showing twin boundaries in extra-large supramolecular polymers.

Table S1: Results of hydrogen production and IQE experiments for the supramolecular polymers. Control samples are labeled "aged", and extra-large supramolecular polymers are labeled "annealed".

\begin{tabular}{cc:c|c:c} 
Light Source & \multicolumn{2}{c}{ TON $(18 \mathrm{hr})$} & \multicolumn{2}{c}{ IQE (\%) } \\
\cline { 2 - 5 } Halogen Lamp & $3425 \pm 476$ & $5423 \pm 479$ & N/A & N/A \\
$447 \mathrm{~nm}$ LED & $1722 \pm 187$ & $2223 \pm 408$ & $0.078 \pm 0.008$ & $0.087 \pm 0.014$ \\
$505 \mathrm{~nm}$ LED & $469 \pm 47$ & $1221 \pm 236$ & $0.059 \pm 0.003$ & $0.126 \pm 0.021$ \\
$567 \mathrm{~nm}$ LED & $744 \pm 137$ & $1232 \pm 80$ & $0.076 \pm 0.014$ & $0.105 \pm 0.016$ \\
\hline
\end{tabular}

$\mathrm{n}=4$ for LEDs, $\mathrm{n}=8$ for Halogen 

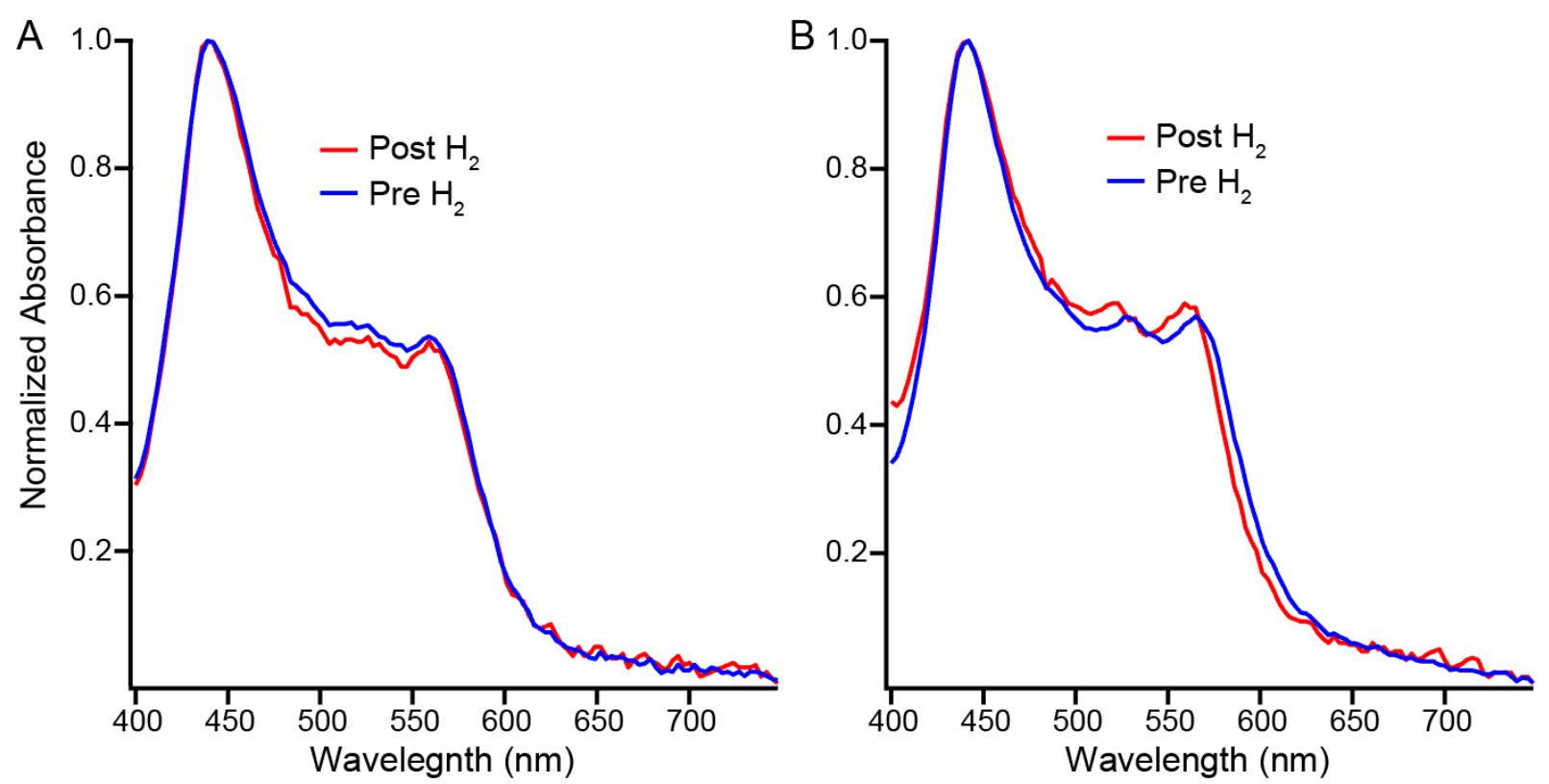

Figure S18: Absorption spectra for photocatalytic supramolecular polymer hydrogels before and after 18 hours of irradiation during $\mathrm{H}_{2}$ production experiments. (A) Gel prepared from $100 \mu \mathrm{L}$ of the control supramolecular polymer solution $(100 \mu \mathrm{L}, 9.6 \mathrm{mM}$ in $50 \mathrm{mM} \mathrm{NaCl}$ aq $)$ with addition of PDDA (20 $\mu \mathrm{L}, 5 \mathrm{wt} \%)$ and ascorbic acid $(900 \mu \mathrm{L}, 1.7 \mathrm{M}$ at $\mathrm{pH} 4)$. (B) Gel prepared from the extra-large supramolecular polymer solution via the same method. 


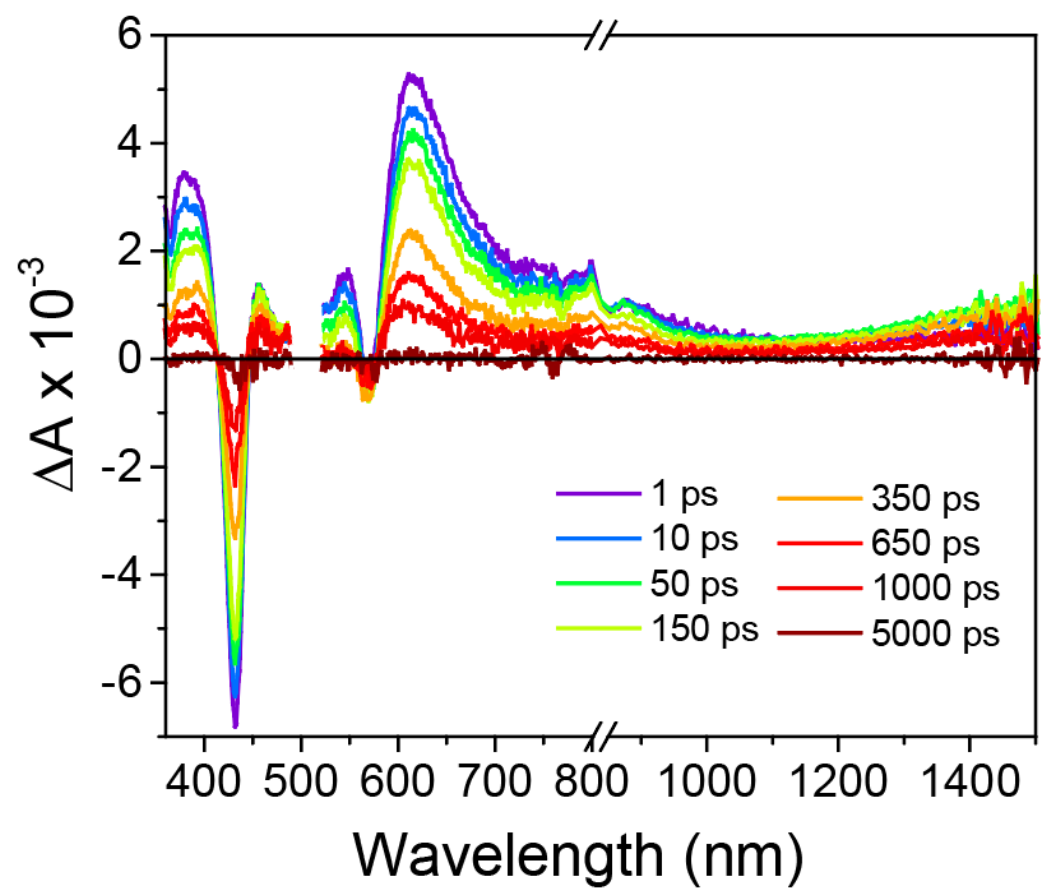

Figure S19: Femtosecond transient absorption spectra of the extra-large supramolecular polymer of $1(9.6 \mathrm{mM}$ in $50 \mathrm{mM}$ $\left.\mathrm{NaCl}_{\mathrm{aq}}\right)$ excited at $505 \mathrm{~nm}(600 \mathrm{~nJ})$

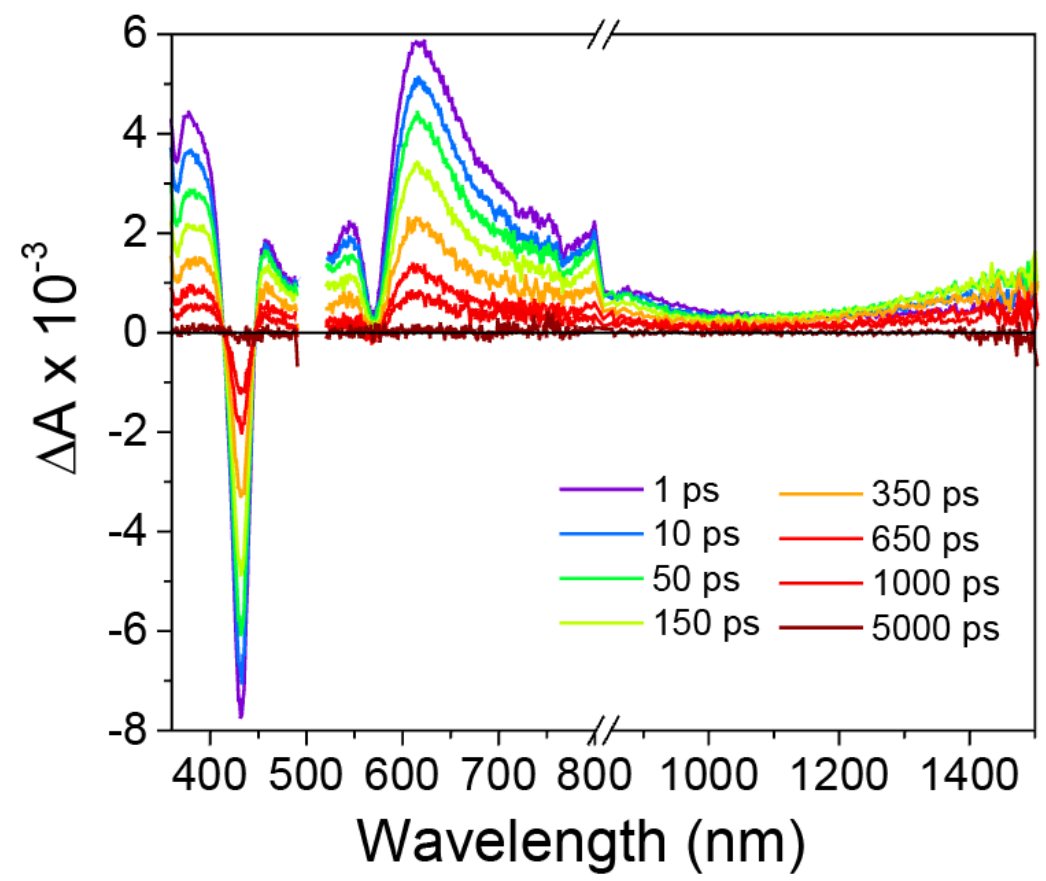

Figure S20: Femtosecond transient absorption spectra of the control supramolecular polymers of $\mathbf{1}\left(9.6 \mathrm{mM}\right.$ in $\left.50 \mathrm{mM} \mathrm{NaCl}_{\mathrm{aq}}\right)$ excited at $505 \mathrm{~nm}(600 \mathrm{~nJ})$. 


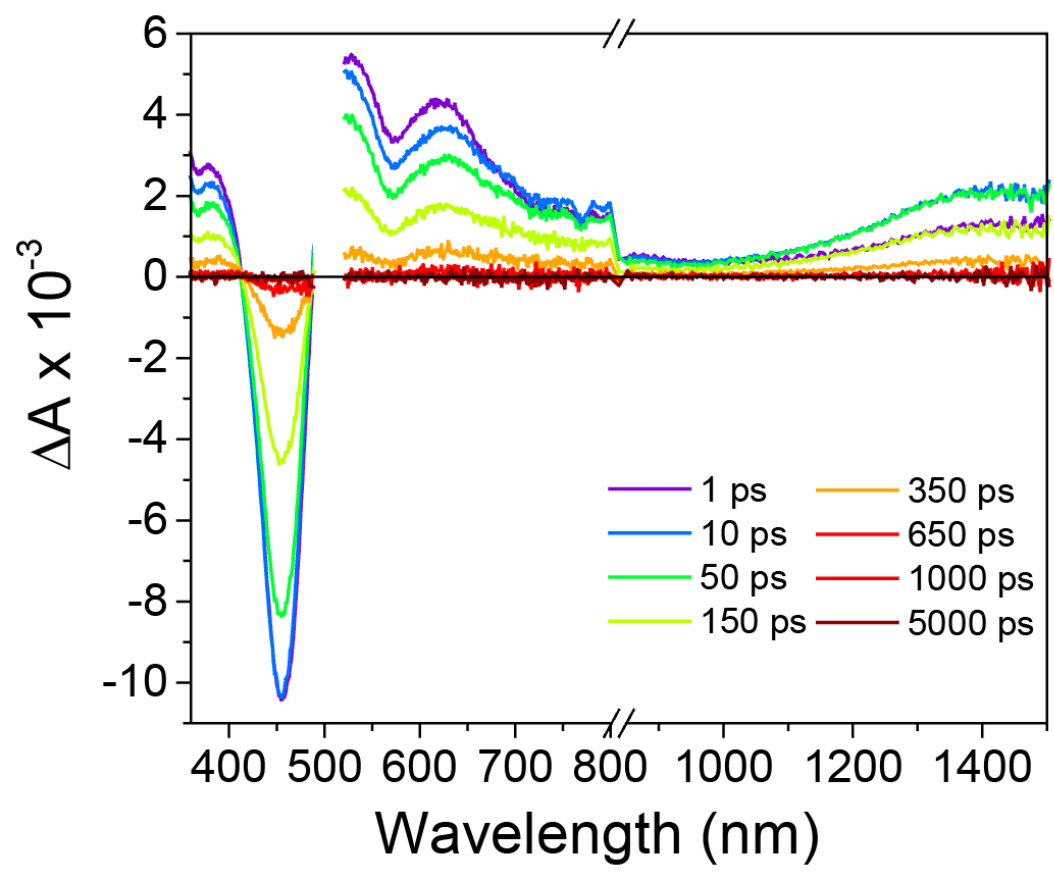

Figure S21: Femtosecond transient absorption spectra of 1 in aqueous solution $(9.6 \mathrm{mM})$ without sodium chloride addition, excited at $505 \mathrm{~nm}(600 \mathrm{~nJ})$

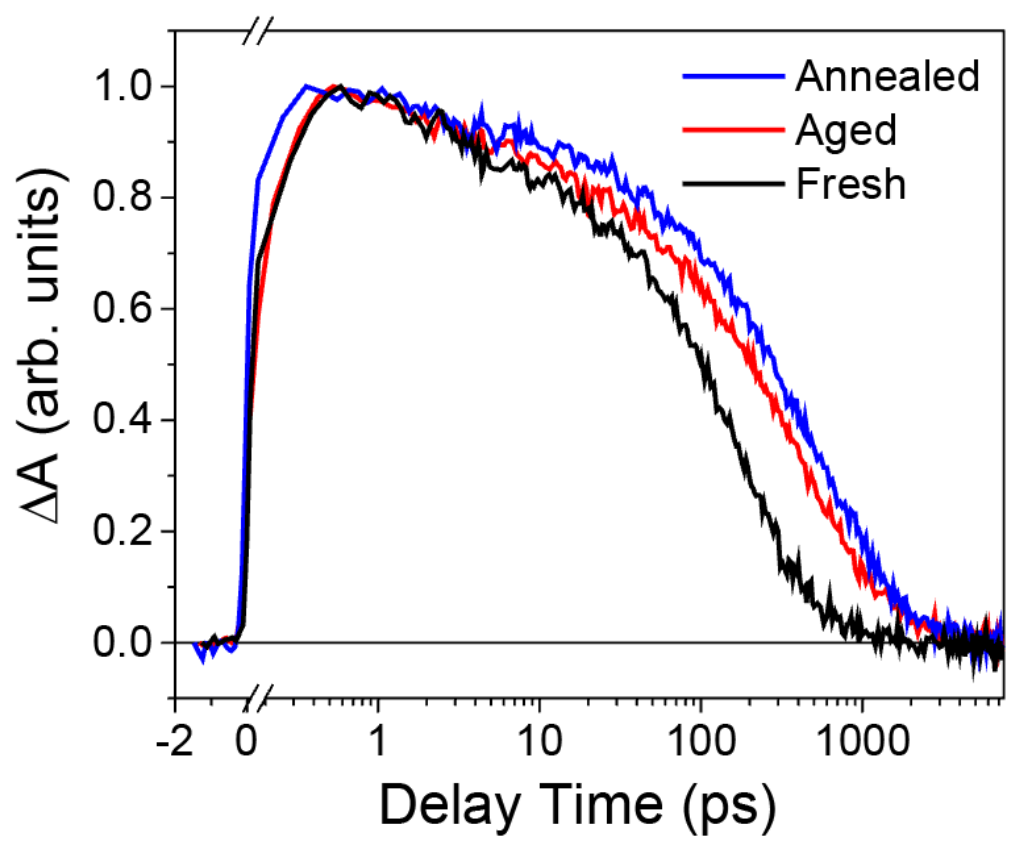

Figure S22: Kinetic traces monitoring band at $671 \mathrm{~nm}$ of the solutions of 1 containing extra-large supramolecular polymer (blue), control supramolecular polymer (red), and before the addition of sodium chloride (black) after excitation at $505 \mathrm{~nm}$. 


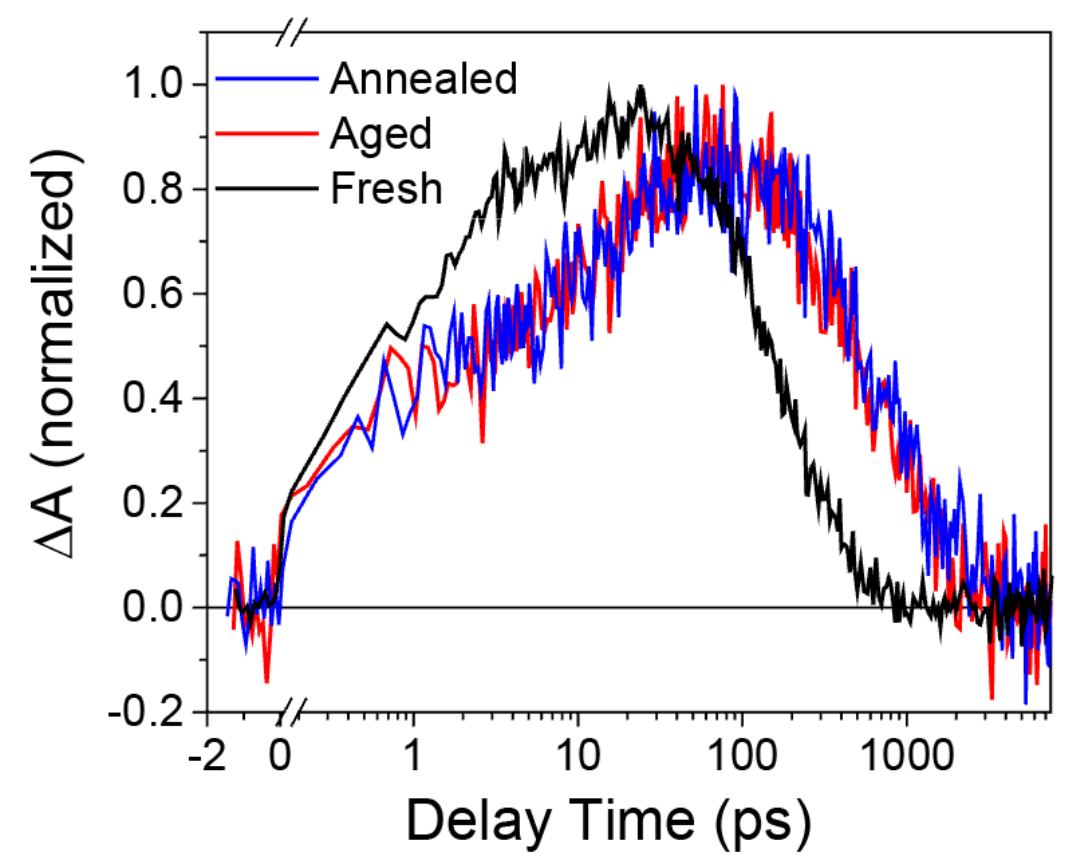

Figure S23: Kinetic traces monitoring band at $1400 \mathrm{~nm}$ of the solutions of 1 containing extra-large supramolecular polymer (blue), control supramolecular polymer (red), and before the addition of sodium chloride (black)after excitation at $505 \mathrm{~nm}$.

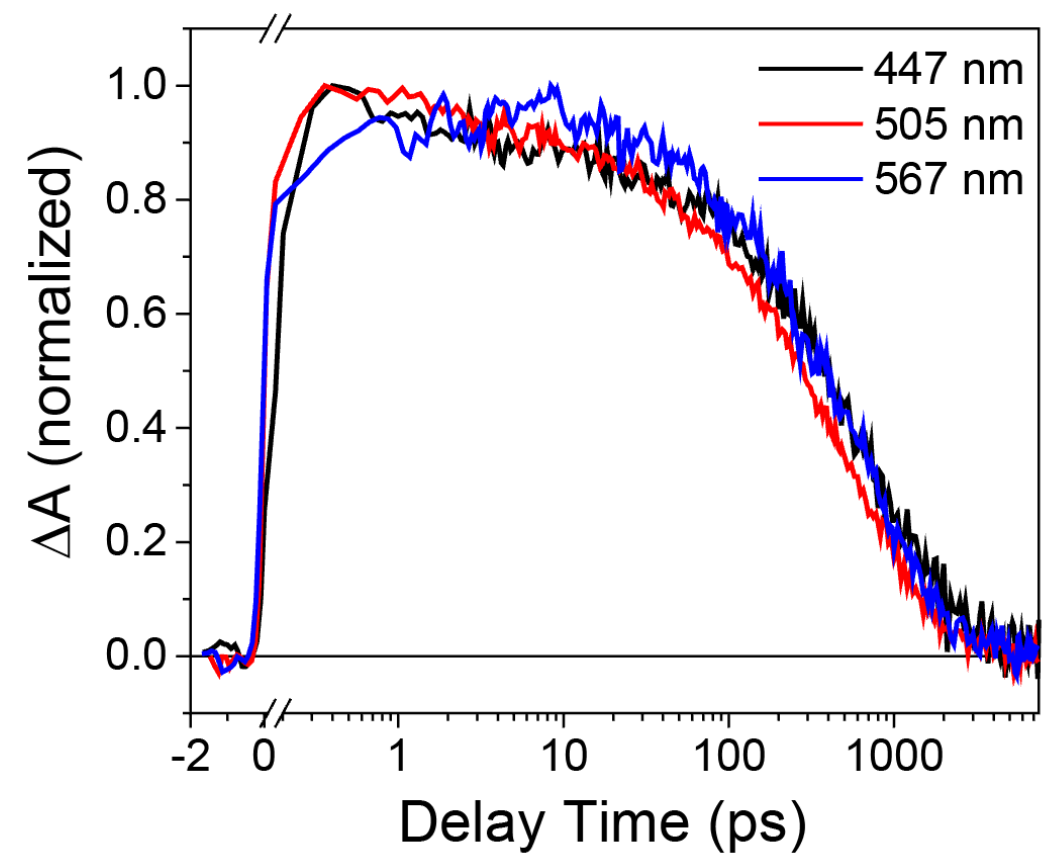

Figure S24: Kinetic traces monitoring band at $671 \mathrm{~nm}$ of the extra-large supramolecular polymer of $1(9.6 \mathrm{mM}$ in $50 \mathrm{mM}$ $\mathrm{NaCl}_{\mathrm{aq}}$ ) after excitation at 447, 505, and $567 \mathrm{~nm}$. 


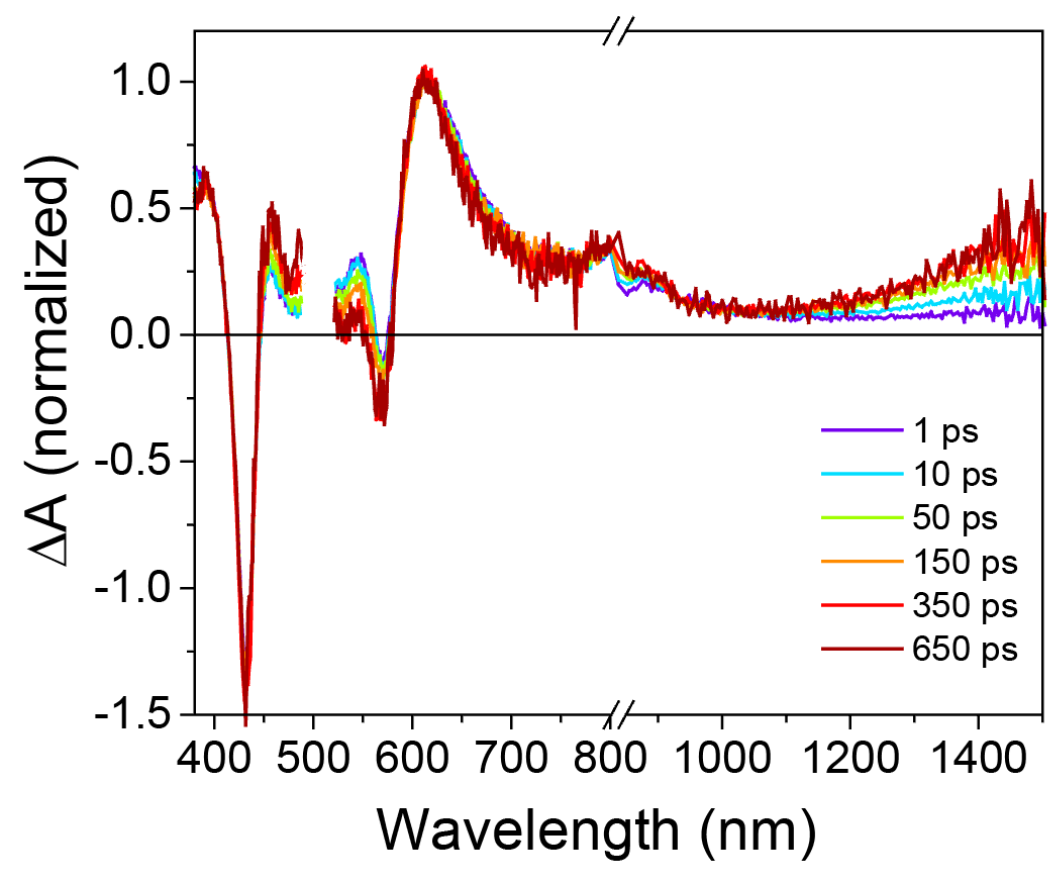

Figure S25: Femtosecond transient absorption spectra of extralarge supramolecular polymer of 1 (9.6 $\mathrm{mM}$ in $50 \mathrm{mM} \mathrm{NaClaq}$ ) excited at $505 \mathrm{~nm}(600 \mathrm{~nJ})$, normalized at $617 \mathrm{~nm}$. Band at 1400 $\mathrm{nm}$ increase in intensity relative to other bands over the first 650 pico seconds. 

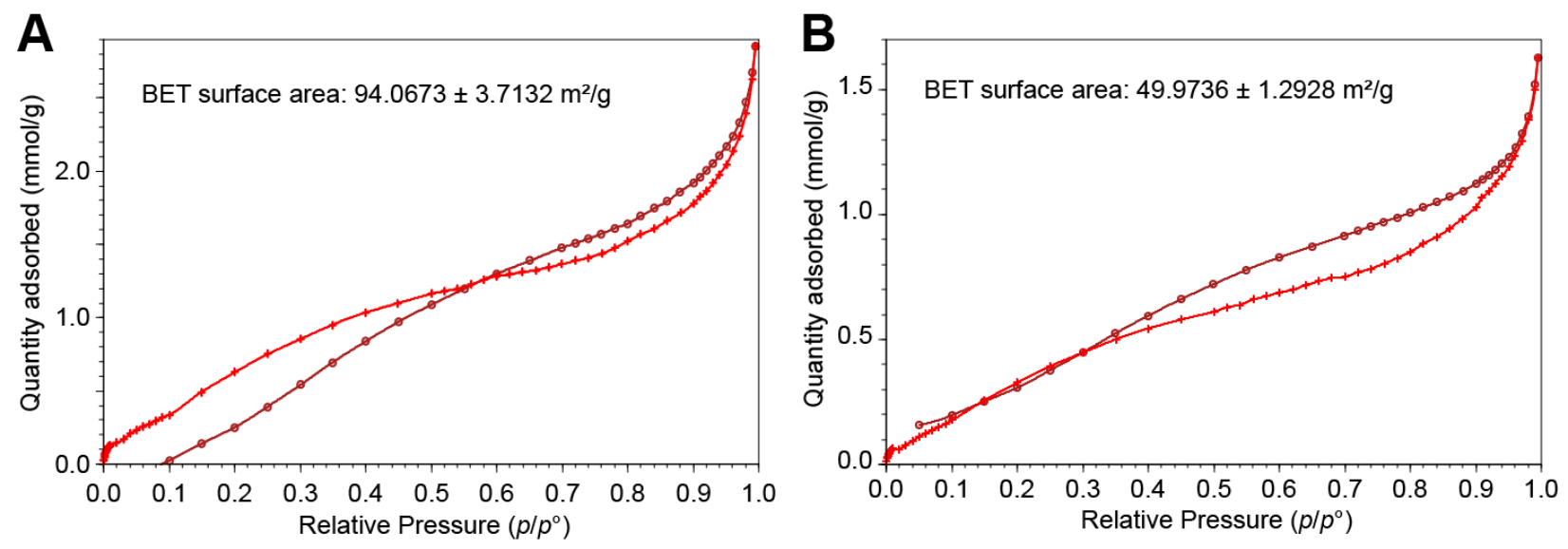

Figure S26: Nitrogen sorption isotherms for (A) extra-large and (B) control supramolecular polymer scaffolds crosslinked with calcium chloride and freeze-dried. Note that the limited amount of materials led to errors in quantities adsorbed, especially for (A). This error underestimates the quantity adsorbed, and thus provides a lower estimate for the BET surface area.

SI Video 1: VT CLSM time-lapse images of 1 (9.6 mM in $50 \mathrm{mM} \mathrm{NaClaq}$ ). The video is accelerated 150 times. 


\section{References}

1. Kazantsev, R. V.; Dannenhoffer, A. J.; Aytun, T.; Harutyunyan, B.; Fairfield, D. J.; Bedzyk, M. J.; Stupp, S. I., Molecular Control of Internal Crystallization and Photocatalytic Function in Supramolecular Nanostructures. Chem 2018, 4 (7), 1596-1608.

2. Kibsgaard, J.; Jaramillo, T. F.; Besenbacher, F., Building an Appropriate Active-Site Motif into a Hydrogen-Evolution Catalyst with Thiomolybdate $\left[\mathrm{Mo}_{3} \mathrm{~S}_{13}\right]^{2-}$ Clusters. Nat. Chem. 2014, 6 (3), 248-253.

3. $\quad$ Fedin, V. P.; Czyzniewska, J.; Prins, R.; Weber, T., Supported Molybdenum-Sulfur Cluster Compounds as Precursors for HDS Catalysts. Appl. Catal. A 2001, 213 (1), 123-132.

4. Weigand, S. J.; Keane, D. T., Dnd-Cat's New Triple Area Detector System for Simultaneous Data Collection at Multiple Length Scales. Nucl. Instrum. Methods Phys. Res 2011, 649 (1), 61-63.

5. Toby, B. H.; Von Dreele, R. B., GSAS-II: The Genesis of a Modern Open-Source All Purpose Crystallography Software Package. J. Appl. Crystallogr. 2013, 46 (2), 544-549.

6. Jiang, Z., GIXSGUI: A Matlab Toolbox for Grazing-Incidence X-Ray Scattering Data Visualization and Reduction, and Indexing of Buried Three-Dimensional Periodic Nanostructured Films. J. Appl. Cryst. 2015, 48 (3), 917-926.

7. Harutyunyan, B.; Dannenhoffer, A.; Kewalramani, S.; Aytun, T.; Fairfield, D. J.; Stupp, S. I.; Bedzyk, M. J., Molecular Packing of Amphiphilic Nanosheets Resolved by X-Ray Scattering. J. Phys. Chem. C 2017, 121 (2), 1047-1054.

8. Kazantsev, R. V.; Dannenhoffer, A. J.; Weingarten, A. S.; Phelan, B. T.; Harutyunyan, B.; Aytun, T.; Narayanan, A.; Fairfield, D. J.; Boekhoven, J.; Sai, H.; Senesi, A.; O'Dogherty, P. I.; Palmer, L. C.; Bedzyk, M. J.; Wasielewski, M. R.; Stupp, S. L., Crystal-Phase Transitions and Photocatalysis in Supramolecular Scaffolds. J. Am. Chem. Soc. 2017, 139 (17), 6120-6127.

9. Harutyunyan, B. X-Ray Scattering Studies of Novel Photoactive Materials. Ph D. Thesis, Northwestern University, 2018.

10. Schindelin, J.; Arganda-Carreras, I.; Frise, E.; Kaynig, V.; Longair, M.; Pietzsch, T.;

Preibisch, S.; Rueden, C.; Saalfeld, S.; Schmid, B.; Tinevez, J.-Y.; White, D. J.; Hartenstein, V.; Eliceiri, K.; Tomancak, P.; Cardona, A., Fiji: An Open-Source Platform for Biological-Image Analysis. Nat. Methods 2012, 9 (7), 676-682.

11. Christensen, J.; Phelan, B.; Chaudhuri, S.; Acharya, A.; Batista, V.; Wasielewski, M., Phenothiazine Radical Cation Excited States as Super-Oxidants for Energy Demanding Reactions. J. Am. Chem. Soc. 2018.

12. Young, R. M.; Dyar, S. M.; Barnes, J. C.; Juríček, M.; Stoddart, J. F.; Co, D. T.;

Wasielewski, M. R., Ultrafast Conformational Dynamics of Electron Transfer in Exbox ${ }^{4+} \subset$ Perylene. J. Phys. Chem. A 2013, 117 (47), 12438-12448.

13. Greenfield, S. R.; Wasielewski, M. R., Near-Transform-Limited Visible and near-Ir Femtosecond Pulses from Optical Parametric Amplification Using Type II $\beta$-Barium Borate. Opt. Lett. 1995, 20 (12), 1394-1396. 